\title{
Onda corta para el dolor musculoesquelético. Revisión sistemática
}

\author{
H. Gutiérrez E. ${ }^{1,2}$, P. González M. ${ }^{3}$ y R. Gellona H. ${ }^{3}$ \\ ${ }^{1}$ Universidad de Las Américas. Escuela de Kinesiología, Facultad de Ciencias de la Salud. Santiago, Chile \\ ${ }^{2}$ Centro de Diagnóstico y Tratamiento (CDT). Hospital Clínico San Borja-Arriarán. Santiago, Chile \\ ${ }^{3}$ Universidad de Las Américas. Facultad de Ciencias de la Salud. Santiago, Chile
}

H. Gutiérrez E. et al. Onda corta para el dolor musculoesquelético. Revisión sistemática. Rev Soc Esp Dolor 2013; 20(5): 230-262.

\begin{abstract}
Shortwave is a type of electromagnetic radiation whose frequency band commonly used is $27.12 \mathrm{MHz}$ with a wavelength of $11.6 \mathrm{~m}$, is a one of the most commonly used by physiotherapists for pain management of musculoskeletal origin, will be a synthesis of evidence through a systematic review of randomized controlled clinical trials.

Objetive: To determine whether there is scientific evidence to support the analgesic effectiveness of shortwave therapy in musculoskeletal pathologies source.

Search strategy: We included in the search for randomized clinical trials (RCTs) and controlled clinical trials (CCTs), the databases used were MEDLINE, CINAHL, Central, PEDro, and LILACS.

Results: 26 studies that met our eligibility criteria.

Conclusions: There is moderate evidence that the short and long term PSW to high and low doses reduce pain and improve function; and the CSW to add an exercise program an education does not reduce pain or analgesic consumption reduced in patients with knee OA; there is moderate evidence that shortterm CSW adding to NSAID and exercise program produces a decrease in pain in patients with chronic low back pain.
\end{abstract}

Key words: Short-wave. Electromagnetic radiation. Musculoskeletal pain. Randomized clinical trial. Systematic review.

\section{RESUMEN}

La onda corta es un tipo de radiación electromagnética, cuya banda de frecuencia más comúnmente usada es $27,12 \mathrm{MHz}$ con una longitud de onda de $11,06 \mathrm{~m}$, es una de las modalidades más usadas por los fisioterapeutas para el manejo del dolor de origen musculoesquelético. Se realizará una síntesis de la evidencia a través de una revisión sistemática de ensayos clínicos aleatorizados y controlados.

Objetivo: Determinar si existe evidencia científica que avale la efectividad analgésica de la onda corta en patologías de origen musculoesquelético.

Estrategia de búsqueda: Se incluyeron en la búsqueda ensayos clínicos aleatorizados (ECAs) y ensayos clínicos controlados (ECCs), las bases de datos usadas fueron: MEDLINE, CINAHL, Central, PEDro y LILACS.

Resultados: Se seleccionaron 26 artículos que cumplían con nuestros criterios de elegibilidad.

Conclusión: Existe moderada evidencia de que a corto y largo plazo la OCP a dosis altas y bajas reducen el dolor y mejoran la función; y el adicionar OCC a un programa de ejercicios y educación no disminuye el dolor ni reduce el consumo de analgésicos en pacientes con OA de rodilla; existe moderada evidencia a corto plazo de que adicionar OCC a un programa terapéutico con AINEs y ejercicios produce una disminución del dolor en pacientes con SDL crónico.

Palabras clave: Onda corta. Radiación electromagnética. Dolor musculoesquelético. Ensayo clínico aleatorizado. Revisión sistemática.

\section{INTRODUCCIÓN}

La onda corta (OC) es un tipo de radiación electromagnética (RE) usada por los fisioterapeutas (FT), cuyo rango 
de frecuencia está comprendido entre los 10 y $100 \mathrm{MHz}$ y su longitud de onda entre 3 y $30 \mathrm{~m}$ (1). Desde la primera aplicación que hace d'Arsonval en 1892 se describe que la interacción de la OC con los tejidos biológicos produce calor (2), es por esto que comúnmente también se la denomina "diatermia", aunque este término no es exclusivo para la OC, ya que engloba también a las microondas (MO) cuyo espectro de frecuencia y longitud de onda son diferentes a la OC (300 MHz - $300 \mathrm{GHz} /$ 0,001 - $1 \mathrm{~m}$ respectivamente) (1). Debido a que la OC está en el espectro de las ondas de radio y su señal puede producir interferencia en las comunicaciones, en Estados Unidos la Comisión Federal de Comunicaciones asignó para aplicaciones médicas de OC 13,56, 27,12 y 40,68 MHz (3), aunque la banda de frecuencia más comúnmente usada por los fabricantes de los equipos es de $27,12 \mathrm{MHz}$ con una longitud de onda de 11,06 m (4). La OC puede entregar la energía electromagnética en forma continua o pulsada, usando para ello diferentes tipos de electrodos: placas capacitativas en donde predomina el campo eléctrico y/o bobinas inductivas en que predomina el campo magnético (1). Como agente terapéutico se considera uno de los métodos más importantes de termoterapia profunda $(1,5)$ y tendría algunas ventajas comparativas con respecto a otros agentes físicos: comparado con las compresas húmedo-calientes, hidroterapia y baños de parafina, los efectos de la OC se producen en los tejidos más profundos $(3$ a $5 \mathrm{~cm}$ de penetración) sin producir un incremento considerable de la $\mathrm{T}^{\mathrm{a}}$ de los tejidos más superficiales $(6,7)$; comparado con el ultrasonido, puede abarcar áreas más grandes de tejido en un mismo periodo de tiempo, sin que la radiación experimente cambios en la transmisión debido a la diferencia de impedancia de los tejidos biológicos (1,8-10).

La onda corta continua (OCC) entrega la energía electromagnética en forma continuada sin ninguna interrupción, lo que produce un incremento importante de la energía cinética molecular y, por consiguiente, un aumento de la temperatura del tejido expuesto. Se han descrito una serie de efectos fisiológicos asociados al efecto térmico de la OCC, tales como vasodilatación, incremento de la velocidad de conducción nerviosa, de la tasa metabólica, de la extensibilidad del tejido colágeno y aumento del umbral doloroso $(1,11,12)$.

En el caso de la onda corta pulsada (OCP), la entrega de energía electromagnética se realiza de manera intermitente (13), es decir, el equipo funciona a la misma frecuencia que la OCC, pero la energía de salida se proporciona en forma de trenes de pulsos (14), cuyo rango de duración está entre los 20 y $400 \mu$ s (13). De este modo, la intermitencia en la entrega de energía permitiría que el calor producido por la oscilación del campo electromagnético se pueda disipar por la circulación sanguínea (15), minimizando de esta forma los efectos térmicos de la $\mathrm{OCC}$, es por esto que tradicionalmente la OCP se ha usado por sus supuestos efectos atérmicos $(1,11,12)$. A pesar de esto, la definición sobre el mecanismo de acción de la OCP ha sido objeto de debate y controversia en la literatura, algunos autores sostienen que son los efectos térmicos producto del incremento en la temperatura y el flujo sanguíneo los responsables de los efectos producidos por la OCP (16-20); sin embargo, hay otros autores que postulan la existencia de efectos atérmicos, como la restauración del potencial de membrana e interacciones entre el nivel iónico y molecular, los responsables de los efectos terapéuticos atribuidos a la OCP $(21,22)$. Sin prejuicio de lo señalado anteriormente, la absorción de energía electromagnética en los tejidos siempre se traducirá en cambios térmicos, aunque en el caso de OCP estos debiesen ser imperceptibles, puesto que habrá disipación del calor en los periodos de pausa del pulso, y el paciente no será capaz de percibir el incremento de la temperatura (23). Aunque estudios publicados recientemente han corroborado que la OCP produce un incremento de la temperatura del tejido expuesto, pero este aumento no se relaciona directamente con la percepción térmica descrita por el paciente, mostrando también que la percepción de calor a nivel cutáneo no asegura un incremento directamente proporcional de la temperatura de los tejidos profundos, y ademas es dosis dependiente, vale decir que tiene directa relación con la potencia media total entregada en la aplicación de OCP (24-27). Los efectos fisiológicos atribuidos a la OCP son: incremento del flujo sanguíneo, disminución del dolor y la rigidez articular, disminución del proceso inflamatorio, reducción del edema y favorecimiento de la reparación tisular $(1,5,7,11,12,22,28,29)$.

Aunque la OC es una de las modalidades más tradicionales de electroterapia, y más comúnmente usada por los fisioterapeutas para el manejo del dolor de origen musculoesquelético (22,30-32), no existe claridad ni consenso entre los fisioterapeutas en qué patologías y/o condiciones clínicas se debe usar $(12,33)$, se ha propuesto el uso de OC en injurias de tejidos blandos (traumáticas y postquirúrgicas), artropatías (osteoartritis, artritis reumatoide) y en cuadros de regeneración nerviosa, sin embargo, no existe evidencia publicada en la literatura que avale su uso en algunas de estas patologías (27). El Panel de Expertos de Filadelfia en sus recomendaciones para Guías de práctica clínica, publicadas en el año 2001, encontraron evidencia insuficiente acerca de la efectividad terapéutica de la OC en el manejo del síndrome de dolor lumbar (SDL) agudo, subagudo, crónico o postquirúrgico (34); en el dolor cervical agudo y crónico (35); en la tendinitis cálcica y el dolor inespecífico de hombro (36), por otra parte, existen muy pocas revisiones que hayan estudiado su efectividad clínica $(11,37,38)$ y los estudios primarios incluidos se han enfocado principalmente en la osteoartritis de rodilla (OA). Es conveniente mencionar que, de acuerdo a la fecha de realización y publicación de estas revisiones, los artículos incluidos en ellas son anteriores al año 2000, considerando además el gran volumen de información biomédica publicada en las últimas décadas, creemos que se hace necesario actualizar y ampliar 
los límites de búsqueda de las revisiones que han estudiado el tema. De lo anteriormente expuesto nacen nuestras preguntas de investigación: en pacientes con alguna patología de origen musculoesquelético de curso agudo o crónico, ¿el uso de la OC sola o en conjunto con otras intervenciones terapéuticas presenta algún efecto analgésico que pueda avalar su indicación y uso clínico?, ¿qué tipo de OC y a qué dosis se logra el potencial efecto analgésico de la OC? El tratar de dilucidar estas interrogantes fue lo que motivó la realización de la presente revisión sistemática.

\section{OBJETIVO}

Determinar si existe evidencia científica que avale la efectividad analgésica de la onda corta en patologías de origen musculoesquelético de curso agudo o crónico.

\section{METODOLOGÍA}

\section{Tipos de estudios}

Para la realización de la presente revisión sistemática se desarrolló una estrategia de búsqueda en la cual se incluyeron ensayos clínicos aleatorizados (ECAs) y ensayos clínicos controlados (ECCs) que cumplieran con nuestros criterios de elegibilidad.

\section{Bases de datos}

Se realizó una búsqueda electrónica en las siguientes bases de datos: MEDLINE (www.ncbi.nlm.nih.gov/pubmed acceso el 20/11/12), CINAHL (www.ebscohost.com/ cinahl acceso 21/11/12), CENTRAL (Cochrane) (www. cochrane.org acceso 22/11/12), PEDro (www.pedro.org.au acceso 23/11/12) y LILACS (www.bases.bireme acceso el 24/11/12). Se seleccionaron artículos publicados entre el 1 de enero de 2000 hasta el 20 de noviembre de 2012 .

\section{Términos de la búsqueda}

Los términos de búsqueda de nuestra revisión fueron obtenidos del MeSH (Tesauro de PubMed), Short-wave Therapy, Musculoskeletal Pain, Range of Motion, Recovery of Function.

Que se combinaron con los términos de texto libre: Shortwave diathermy, Deep heat therapy, Pulsed Shortwave therapy. Para llevar a cabo la búsqueda en la base de datos MEDLINE se utilizó la estrategia de búsqueda sensible propuesta en el Handbook Cochrane (39):

1. "Short-wave Therapy" [Mesh]

2. Shortwave Diathermy
3. Deep heat therapy

4. Pulsed Shortwave therapy

5. \#1 OR \#2 OR \#3 OR \#4

6. "Musculoskeletal Pain" [Mesh]

7. "Range of Motion, Articular" [Mesh]

8. "Recovery of Function" [Mesh]

9. Flexibility

10. \#6 OR \#7 OR \#8 OR \#9

11. \#5 AND \#10

12. randomized controlled trial $[\mathrm{pt}]$

13. controlled clinical trial $[\mathrm{pt}]$

14. randomized [tiab]

15. placebo [tiab]

16. drug therapy [sh]

17. randomly [tiab]

18. trial [tb]

19. groups [tiab]

20. \#12 OR \#13 OR \#14 OR \#15 OR \#16 OR \#17 OR \#18 OR \#19

21. animals [mh] NOT humans [mh]

22. \#20 NOT \#21

23. \#11 AND \#22

Para las bases de datos Cinahl, Central, PEDro y Lilacs se realizó la estrategia de búsqueda combinando los términos mencionados previamente en la opción de búsqueda avanzada (Fig.1).

\section{Límites de búsqueda}

- Artículos que hayan estudiado la efectividad analgésica de la onda corta de 27,12 MHz en su modalidad continua y/o pulsada, para el manejo de alguna patología de origen musculoesquelético de curso agudo o crónico.

- Sin distinción de género y raza.

- Artículos publicados en inglés y español.

- Publicados entre el 1 de enero de 2000 hasta el 20 de noviembre de 2012.

\section{Criterios de selección}

A los artículos seleccionados por la búsqueda preliminar, se les aplicó un filtro realizando una lectura crítica a los abstracts y/o texto completo, donde fueron evaluados según los siguientes criterios:

\section{Criterios de inclusión}

- Artículos que hayan estudiado la OC como intervención primaria, de forma aislada o en conjunto con otras intervenciones (parte de un programa de trata- 
miento), para el manejo analgésico de alguna patología musculoesquelética aguda o crónica.

- Artículos que hayan estudiado cualquier intervención terapéutica versus OC para el manejo analgésico de alguna patología musculoesquelética aguda o crónica.

- Artículos que evalúen la efectividad analgésica de la OC, a través de: escalas uni o multidimensionales para valorar el dolor (EVA, Escala numérica, Cuestionario Mc Gill), Escalas o Scores de Funcionalidad y/o Calidad de vida; Rango de Movimiento y/o Flexibilidad (goniómetro).

\section{Criterios de exclusión (Tabla I)}

- Artículos que estudien diatermia con el uso de microondas (MO) y el uso de campos electromagnéticos pulsados (CEP) en una banda de frecuencia diferente a 27,12 MHz.

- Artículos que ocupen solo la OC apagada como intervención placebo o control.

- Artículos experimentales en pacientes sanos (sin patología musculoesquelética).

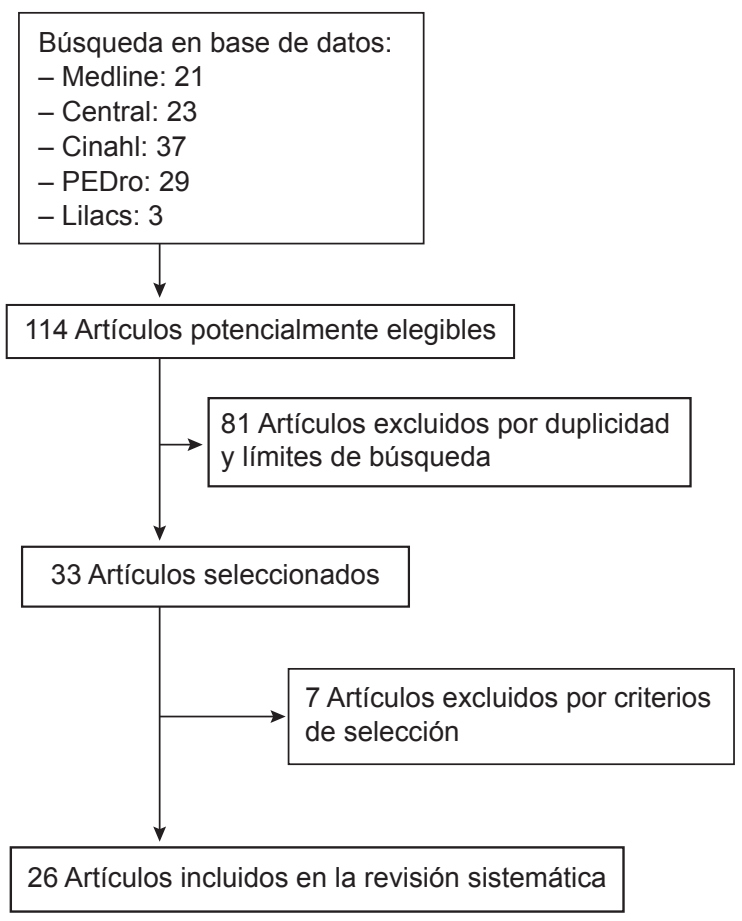

Fig. 1. Algoritmo de búsqueda.

TABLA I. ARTÍCULOS EXCLUIDOS POR CRITERIOS DE SELECCIÓN

\begin{tabular}{|c|c|c|}
\hline Autor & Publicación & Razón de exclusión \\
\hline $\begin{array}{l}\text { Murray CC, Kitchen } S \\
(2000)\end{array}$ & $\begin{array}{l}\text { Effect of pulse repetition rate on the perception of } \\
\text { thermal sensation with pulsed shortwave diathermy. } \\
\text { Physiother Res Int 2000;5(2):73-84 }\end{array}$ & $\begin{array}{l}\text { Estudio clínico aleatorizado en } \\
\text { pacientes sanos (sin patología } \\
\text { musculoesquelética) }\end{array}$ \\
\hline $\begin{array}{l}\text { Lamina } S \text {, Hanif } S \text {, } \\
\text { Gagarawa YS } \\
\text { (2011) }\end{array}$ & $\begin{array}{l}\text { Short wave diathermy in the symptomatic } \\
\text { management of chronic pelvic inflammatory disease } \\
\text { pain: A randomized controlled trial. } \\
\text { Physiother Res Int 2011;16(1):50-6 }\end{array}$ & $\begin{array}{l}\text { Estudio clínico aleatorizado en } \\
\text { inflamación de la pelvis }\end{array}$ \\
\hline $\begin{array}{l}\text { Peres } S E \text {, Draper DO, } \\
\text { Knight KL, Ricard } \\
\text { MD } \\
(2002)\end{array}$ & $\begin{array}{l}\text { Pulsed Shortwave Diathermy and Prolonged Long- } \\
\text { Duration Stretching Increase Dorsiflexion Range } \\
\text { of Motion More Than Identical Stretching Without } \\
\text { Diathermy. } \\
\text { J Athl Train 2002;37(1):43-50 }\end{array}$ & $\begin{array}{l}\text { Articulo experimental en } \\
\text { pacientes sanos (sin patología } \\
\text { musculoesquelética) }\end{array}$ \\
\hline $\begin{array}{l}\text { Draper DO, Miner } \\
\text { L, Knight KL, Ricard } \\
\text { MD } \\
(2002)\end{array}$ & $\begin{array}{l}\text { The Carry-Over Effects of Diathermy and Stretching } \\
\text { in Developing Hamstring Flexibility } \\
\text { J Athl Train 2002;37(1):37-42 }\end{array}$ & $\begin{array}{l}\text { Artículo experimental en } \\
\text { pacientes sanos (sin patología } \\
\text { musculoesquelética) }\end{array}$ \\
\hline
\end{tabular}

The effectiveness of pulsed short-wave diathermy for

Martin $H$

(2004) the treatment of postpartum perineal trauma: a pilot

study.
Journal of the Association Chartered Physiotherapists

Estudio piloto dolor perineal post-

parto

Women's Health 2004;95:17-28 
TABLA I (CONT.). ARTÍCULOS EXCLUIDOS POR CRITERIOS DE SELECCIÓN

\begin{tabular}{|c|c|c|}
\hline Autor & Publicación & Razón de exclusión \\
\hline $\begin{array}{l}\text { Draper DO, Castro } \\
\text { JL, Feland B, } \\
\text { Schulthies } S \text {, Eggett D } \\
(2004)\end{array}$ & $\begin{array}{l}\text { Shortwave diathermy and prolonged stretching } \\
\text { increase hamstring flexibility more than prolonged } \\
\text { stretching alone. } \\
\text { J Orthop Sports Phys Ther 2004;34(1):13-20 }\end{array}$ & $\begin{array}{l}\text { Artículo experimental en } \\
\text { pacientes sanos (sin patología } \\
\text { musculoesquelética) }\end{array}$ \\
\hline $\begin{array}{l}\text { Adegoke } B O \text {, } \\
\text { Gbeminiyi } M O \\
(2004)\end{array}$ & $\begin{array}{l}\text { Efficacy of ice and short-wave diathermy in } \\
\text { the management of osteoarthritis of the knee s } \\
\text { preliminary report. } \\
\text { African Journal of Biomedical Research } \\
2004 ; 7(3): 107-11\end{array}$ & $\begin{array}{l}\text { Reporte preliminar sin publicación de } \\
\text { datos de los grupos de estudio }\end{array}$ \\
\hline $\begin{array}{l}\text { Robertson } V \text {, Ward } A \text {, } \\
\text { Jung } P \\
(2005)\end{array}$ & $\begin{array}{l}\text { The effect of heat on tissue extensibility: a } \\
\text { comparison of deep and superficial heating. } \\
\text { Arch Phys Med Rehabil 2005;86(4):819-25 }\end{array}$ & $\begin{array}{l}\text { Artículo experimental en } \\
\text { pacientes sanos (sin patología } \\
\text { musculoesquelética) }\end{array}$ \\
\hline $\begin{array}{l}\text { Brucker JB, Knight } \\
\text { KL, Rubley } M D \\
\text { Draper DO } \\
(2005)\end{array}$ & $\begin{array}{l}\text { An 18-day stretching regimen, with or without } \\
\text { pulsed, shortwave diathermy, and ankle dorsiflexion } \\
\text { after } 3 \text { weeks. } \\
\text { J Athl Train } 2005 ; 40(4): 276-80\end{array}$ & $\begin{array}{l}\text { Artículo experimental en } \\
\text { pacientes sanos (sin patología } \\
\text { musculoesquelética) }\end{array}$ \\
\hline
\end{tabular}

Costa LO, Maher CG,

Latimer J, Hodges

$P W$, Herbert RD,

Refshauge KM, et al. (2009)

$\begin{array}{ll}\text { Al-Mandeel MM, } & \begin{array}{l}\text { The thermal and nonthermal effects of high and low } \\ \text { doses of pulsed short wave therapy (PSWT). } \\ \text { Watson T (2010) }\end{array} \\ \end{array}$

Castro A, Mataran G, Arroyo M, Saavedra $M$, Fernández $C$, Moreno C (2011)

Motor control exercise for chronic low back pain: A randomized placebo-controlled trial. Physical Therapy 2009;89(12):1275-86

Artículo que utiliza la OC apagada como intervención placebo

Artículo experimental en pacientes sanos (sin patología musculoesquelética

Effects of myofascial release techniques on pain, physical function, and postural stability in patients with fibromyalgia: a randomized controlled trial. Clin Rehabil 201;25(9):800-13
Artículo que utiliza solo la OC apagada como intervención placebo
Carr JL, Klaber

Moffett JA, Howarth

E, Richmond SJ,

Torgerson DJ,

Jackson DA, et al. (2005)

\section{Draper DO}

(2011)

Evans $R$, Knight $K$, Draper D, Parcell A (2002)

\section{Giombini A, Di}

Cesare A, Safran M, Ciatti R, Maffulli $N$ (2006)
A randomized trial comparing a group exercise programme for back pain patients with individual physiotherapy in a severely deprived area.

Disability and Rehabilitation 2005;27(16):929-37
Estudio clínico aleatorizado en que no todos los pacientes del grupo control recibieron OC (solo el $11 \%$ )
Injuries restored to ROM using PSWD and mobilizations.

Int J Sports Med 201;32(4):281-6

Effects of warm-up before eccentric exercise on indirect markers of muscle damage. Med Sci Sports Exerc 2002;34(12):1892-9

Short-term effectiveness of hyperthermia for supraspinatus tendinopathy in athletes: A short-term randomized controlled study. Am J Sports Med 2006;34(8):1247-53
Serie de casos

Artículo experimental en pacientes sanos (sin patología musculoesquelética)

Estudio clínico aleatorizado que usa diatermia por microondas (MO) 
TABLA I (CONT.). ARTÍCULOS EXCLUIDOS POR CRITERIOS DE SELECCIÓN

\begin{tabular}{lll}
\hline \multicolumn{1}{c}{ Autor } & \multicolumn{1}{c}{ Publicación } & \multicolumn{1}{c}{ Razón de exclusión } \\
\hline Rabini A, Piazzini D, & Effects of Local Microwave Diathermy on Shoulder & \\
Bertolini C, Deriu & Pain and Function in Patients With Rotator Cuff & \\
L, Saccomanno M, & Tendinopathy in Comparison to Subacromial & Estudio clínico aleatorizado que usa \\
Santagada D et al. & Corticosteroid Injections: A Single-Blind & Randomized Trial \\
(2012) & J Orthop Sports Phys Ther 2012;42(4):363-70 & \\
\end{tabular}

\section{Evaluación de la calidad metodológica de los artículos seleccionados (Tabla II)}

Según los criterios de selección de nuestra revisión, 26 artículos quedaron incluidos (40-65). La calidad metodológica de estos estudios fue evaluada con la escala de PEDro (Physiotherapy Evidence Database) (66). Dicha escala tiene validada algunas de sus propiedades psicométricas, con una buena confiabilidad en cuanto a su aplicación (67-70), proporcionando una medida global de la calidad metodológica a través de la valoración de 11 criterios. El criterio $\mathrm{n}^{\mathrm{o}} 1$ evalúa la validez externa y no está incluido en el resultado final, del criterio 2 al 11 se evalúa la validez interna del artículo con un sistema de puntuación estandarizado, en que si se cumple cada criterio se contribuye con 1 punto al resultado final (rango de 0 a 10), un estudio se considera de baja calidad metodológica si tiene menos de 4 puntos (71) y de alta calidad metodológica si tiene un puntaje de PEDro mayor a 6 puntos $(67,72)$.

TABLA II. CALIDAD METODOLÓGICA DE LOS ARTÍCULOS INCLUIDOS SEGÚN ESCALA DE PEDRO

\begin{tabular}{|c|c|c|c|c|c|c|c|c|c|c|c|c|}
\hline Estudio & $\begin{array}{l}\text { Criterios de } \\
\text { elegibilidad }\end{array}$ & $\begin{array}{c}\text { Asignación } \\
\text { aleatoria }\end{array}$ & $\begin{array}{l}\text { Se ocultó la } \\
\text { asignación }\end{array}$ & $\begin{array}{c}\text { Grupos } \\
\text { similares en la } \\
\text { linea de base }\end{array}$ & $\begin{array}{l}\text { Sujetos } \\
\text { fueron } \\
\text { cegados }\end{array}$ & $\begin{array}{c}\text { Terapeutas } \\
\text { cegados }\end{array}$ & $\begin{array}{c}\text { Evaluadores } \\
\text { cegados }\end{array}$ & $\begin{array}{l}\text { Seguimiento } \\
\text { adecuado }\end{array}$ & $\begin{array}{c}\text { Análisis } \\
\text { intención de } \\
\text { tratar }\end{array}$ & $\begin{array}{c}\text { Análisis } \\
\text { comparación } \\
\text { de los grupos }\end{array}$ & $\begin{array}{c}\text { Variabilidady } \\
\text { estimaciones } \\
\text { puntuales }\end{array}$ & $\begin{array}{l}\text { Puntaje } \\
\text { final }\end{array}$ \\
\hline $\begin{array}{l}\text { Ahmed et } \\
\text { al. (59) }\end{array}$ & Sí & Sí & No & No & Sí & No & Sí & Sí & No & Sí & Sí & 6 \\
\hline $\begin{array}{l}\text { Akyol et al. } \\
(40)\end{array}$ & Sí & Sí & Sí & Sí & No & No & Sí & Sí & No & Sí & Sí & 7 \\
\hline $\begin{array}{l}\text { Atamaz et } \\
\text { al. (41) }\end{array}$ & Sí & Sí & No & Sí & No & No & No & Sí & No & Sí & Sí & 5 \\
\hline $\begin{array}{l}\text { Atamaz et } \\
\text { al. (42) }\end{array}$ & Sí & Sí & No & Sí & Sí & No & Sí & Sí & Sí & Sí & Sí & 8 \\
\hline $\begin{array}{l}\text { Bezalel et } \\
\text { al. (43) }\end{array}$ & Sí & Sí & No & Sí & No & No & Sí & No & Sí & Sí & Sí & 6 \\
\hline $\begin{array}{l}\text { Bindal et } \\
\text { al. }(60)\end{array}$ & Sí & Sí & No & Sí & No & No & No & Sí & Sí & No & Sí & 5 \\
\hline $\begin{array}{l}\text { Buzzard et } \\
\text { al. (58) }\end{array}$ & Sí & No & No & No & No & No & No & No & No & Sí & Sí & 2 \\
\hline $\begin{array}{l}\text { Callaghan } \\
\text { et al. (44) }\end{array}$ & Sí & Sí & Sí & Sí & No & No & Sí & No & No & Sí & Sí & 6 \\
\hline $\begin{array}{l}\text { Cantarini } \\
\text { et al. (45) }\end{array}$ & Sí & Sí & No & Sí & No & No & No & Sí & No & Sí & No & 4 \\
\hline $\begin{array}{l}\text { Cetin et al. } \\
(46)\end{array}$ & Sí & Sí & No & Sí & No & No & Sí & Sí & No & Sí & Sí & 6 \\
\hline $\begin{array}{l}\text { Dziedzic et } \\
\text { al. (56) }\end{array}$ & Sí & Sí & Sí & Sí & No & No & Sí & Sí & Sí & Sí & Sí & 8 \\
\hline $\begin{array}{l}\text { Fukuda et } \\
\text { al. (47) }\end{array}$ & Sí & Sí & No & No & No & No & Sí & Sí & No & Sí & Sí & 5 \\
\hline
\end{tabular}


TABLA II (CONT.). CALIDAD METODOLÓGICA DE LOS ARTÍCULOS INCLUIDOS SEGÚN ESCALA DE PEDRO

\begin{tabular}{|c|c|c|c|c|c|c|c|c|c|c|c|c|}
\hline Estudio & $\begin{array}{l}\text { Criterios de } \\
\text { elegibilidad }\end{array}$ & $\begin{array}{l}\text { Asignación } \\
\text { aleatoria }\end{array}$ & $\begin{array}{l}\text { Se ocultóla } \\
\text { asignación }\end{array}$ & $\begin{array}{c}\text { Grupos } \\
\text { similares en la } \\
\text { linea de base }\end{array}$ & $\begin{array}{l}\text { Sujetos } \\
\text { fueron } \\
\text { cegados }\end{array}$ & $\begin{array}{l}\text { Terapeutas } \\
\text { cegados }\end{array}$ & $\begin{array}{l}\text { Evaluadores } \\
\text { cegados }\end{array}$ & $\begin{array}{l}\text { Seguimiento } \\
\text { adecuado }\end{array}$ & $\begin{array}{l}\text { Análisis } \\
\text { intención de } \\
\text { tratar }\end{array}$ & $\begin{array}{c}\text { Análisis } \\
\text { comparación } \\
\text { de los grupos }\end{array}$ & $\begin{array}{c}\text { Variabilidady } \\
\text { estimaciones } \\
\text { puntuales }\end{array}$ & $\begin{array}{l}\text { Puntaje } \\
\text { final }\end{array}$ \\
\hline $\begin{array}{l}\text { Fukuda et } \\
\text { al. (48) }\end{array}$ & Sí & Sí & Sí & Sí & Sí & No & Sí & Sí & Sí & Sí & Sí & 9 \\
\hline $\begin{array}{l}\text { Guler- } \\
\text { Uysal et al. } \\
(63)\end{array}$ & Sí & Sí & No & Sí & No & No & Sí & Sí & No & Sí & Sí & 6 \\
\hline $\begin{array}{l}\text { Jan et al. } \\
\text { (49) }\end{array}$ & Sí & Sí & No & Sí & No & No & No & No & No & Sí & Sí & 4 \\
\hline $\begin{array}{l}\text { Jiménez et } \\
\text { al. (64) }\end{array}$ & Sí & Sí & No & Sí & No & No & No & No & No & Sí & Sí & 4 \\
\hline $\begin{array}{l}\text { Kumar et } \\
\text { al. (61) }\end{array}$ & Sí & Sí & No & No & No & No & No & Sí & No & Sí & Sí & 4 \\
\hline $\begin{array}{l}\text { Laufer et } \\
\text { al. }(50)\end{array}$ & Sí & No & No & Sí & Sí & No & Sí & Sí & No & Sí & Sí & 6 \\
\hline $\begin{array}{l}\text { Leung et al. } \\
(65)\end{array}$ & Sí & Sí & No & Sí & No & No & Sí & Sí & No & Sí & Sí & 6 \\
\hline $\begin{array}{l}\text { Lewis et al. } \\
(57)\end{array}$ & Sí & Sí & No & No & No & No & No & Sí & Sí & No & Sí & 4 \\
\hline $\begin{array}{l}\text { Ovanessian } \\
\text { et al. (51) }\end{array}$ & Sí & Sí & No & No & No & Sí & No & Sí & No & Sí & Sí & 5 \\
\hline $\begin{array}{l}\text { Rattanachaivanont } \\
\text { et al. (52) }\end{array}$ & Sí & Sí & Sí & Sí & Sí & No & Sí & Sí & Sí & Sí & Sí & 9 \\
\hline $\begin{array}{l}\text { Shakoor et } \\
\text { al. (53) }\end{array}$ & Sí & Sí & No & No & No & No & No & Sí & Sí & Sí & Sí & 5 \\
\hline $\begin{array}{l}\text { Shakoor et } \\
\text { al. }(62)\end{array}$ & Sí & Sí & No & Sí & No & No & No & No & No & Sí & Sí & 4 \\
\hline $\begin{array}{l}\text { Silva et al. } \\
(54)\end{array}$ & Sí & Sí & No & No & No & Sí & No & No & No & Sí & Sí & 4 \\
\hline $\begin{array}{l}\text { Tuzun et al. } \\
\text { (55) }\end{array}$ & Sí & Sí & No & Sí & No & No & No & No & No & Sí & Sí & 4 \\
\hline
\end{tabular}

\section{Recopilación de datos}

Dos de los autores (RG y PG) realizaron la cadena de búsqueda en forma independiente, seleccionando los artículos que eran potencialmente elegibles, y evaluaron la calidad metodológica de los artículos seleccionados. En caso de desacuerdo y/o discrepancia, los autores acordaron incorporar el artículo y someterlo al análisis de un asesor independiente (FA) para decidir mediante discusión y consenso su inclusión final.

\section{Síntesis y análisis de datos}

De acuerdo con el análisis de los datos extraídos de los artículos que cumplían los criterios de elegibilidad de nuestra RS, hubo 3 comparaciones que aparentemente cumplían con la condición de homogeneidad clínica: los grupos 5 y 6 del estudio de Cetin et al. (46) y Rattanachaiyanont et al. (52) compararon OCC más un programa de ejercicios versus OCC apagada más un programa de ejercicios en pacientes con OA de rodilla; los estudios 
de Dziedzic et al. (56) y Lewis et al. (57) compararon el adicionar terapia manual versus adicionar OCP a un programa de ejercicios más asesoramiento en pacientes con dolor cervical inespecífico; los estudios de Ahmed et al. (59) y el de Shakoor et al. (62) compararon OCC, AINEs y ejercicios versus OCC placebo (máquina apagada), AINEs y ejercicios en pacientes con Síndrome de dolor lumbar crónico. Si bien es cierto que estas 3 comparaciones eran, a priori, homogéneas desde el punto de vista clínico, por motivos que se detallan más adelante, los realizadores de la presente RS no consideramos plausible realizar la comparación según el análisis de la homogeneidad estadística y eventual cálculo de un estimador puntual. Situación diferente fue el caso de los 3 artículos $(47,48,51)$ que compararon diferentes dosis de OCP en pacientes con OA crónica de rodilla, pues eran clínicamente homogéneos, pero las publicaciones no reportaban los datos de las medidas de resultado estudiadas por grupos, por lo cual se contactó al grupo de autores de manera de requerir esta información, se pudo establecer contacto vía correo electrónico con el Sr. Thiago Fukuda, quien nos respondió que no contaba con los datos grupales de la medición de dolor; por esta razón, no pudimos agrupar los datos de estos 3 estudios en un estimador puntual, para ver la posibilidad de realizar un metaanálisis.

\section{Criterios para valoración de los resultados}

Para el resto de las comparaciones realizadas por nuestra revisión, no existía homogeneidad clínica que permitiera agrupar los datos de algunos de los estudios según un estimador puntual, por lo tanto, ni siquiera fue posible evaluar la homogeneidad estadística y llevar a cabo un metaanálisis.

Por este motivo, se utilizará un método cualitativo recomendado por el Grupo Cochrane de Espalda (Van Tulder, 2003) con el uso de niveles de evidencia para la síntesis de los datos (73).

- Evidencia sólida: proporcionada por hallazgos generalmente consistentes en múltiples ECAs (3 o más) de alta calidad metodológica.

- Evidencia moderada: proporcionada por resultados generalmente consistentes en 1 ECA de alta calidad metodológica, también se puede interpretar como hallazgos generalmente consistentes en múltiples ECAs con moderada calidad metodológica.

- Evidencia limitada: proporcionada por hallazgos consistentes en 1 o más ECAs de baja calidad metodológica.

- Evidencia contradictoria: hallazgos no coherentes o inconsistentes en múltiples ECAs.

- Ninguna evidencia: ningún ECA encontrado.

\section{RESULTADOS}

\section{Selección y características de los estudios}

De acuerdo con los criterios de nuestra revisión, la búsqueda preliminar identificó 114 artículos potencialmente elegibles; al aplicar los límites de búsqueda y los criterios de selección, quedaron 26 estudios. En los 26 ECAs seleccionados (40-65) ( $\mathrm{n}=2.371$ pacientes), los tamaños de la muestra variaron entre 20 y 350 pacientes con un promedio de 91 pacientes por estudio y el rango de edad estaba entre 17 y 84 años con un promedio de 50 años.

\section{Intervenciones y comparaciones}

Las intervenciones terapéuticas fueron: el uso de OC sola y OC en conjunto con otras intervenciones. Según los resultados de nuestra búsqueda agrupamos los artículos seleccionados en las siguientes comparaciones: OC sola versus otra intervención sola (58); OC sola versus un programa de tratamiento $(43,45,49)$; programa de tratamiento que incluya OC versus otra intervención sola $(40,61)$; programa de tratamiento que incluya $\mathrm{OC}$ versus otro programa de tratamiento $(41,42,46,52-54,56,57,59,60,62-65)$; comparaciones entre diferentes dosis de OC $(44,47,48,50,51,55)$.

\section{Medidas de resultado}

Las medidas de resultado más comúnmente utilizadas en los artículos seleccionados fueron: dolor medido con Escala Visual Análoga (EVA) (40-42,44-47,49,51,53,55,6164), Lattinen Test Score (LTS) $(53,59,62)$, Northwick Park Neck Pain Questionnaire (NPQ) $(56,57)$ y consumo de analgésicos $(42,45,52)$. Para medir la funcionalidad se utilizaron: pruebas funcionales como tiempo de caminar (40-42,44,46,50,52,55,61), Western Ontario and Mc Master University Osteoarthritis (WOMAC) (40-42,50,52), Lequesne Algofunctional Questionnaire (ALQ) $(45-47,54)$, Knee and Osteoarthritis Outcome Score (KOOS) $(48,51)$ y rango de movimiento con goniómetro $(41,42,44,47,51,53$ $55,58,63,65) ; 13$ de los artículos seleccionados no contemplaban seguimiento en su diseño $(44,46,47,51,53-55,58,59,61$ 64), 8 artículos investigaron los efectos a corto plazo (menos de 3 meses) (40,43,45,49,50,52,60,65), 3 artículos realizaron un seguimiento a mediano plazo $(42,56,57)$ y solo 2 realizaron un seguimiento a largo plazo (1 año) $(41,48)$.

\section{Resultados}

El resumen de todos los aspectos metodológicos de los artículos seleccionados se detallan en las Tablas III-VII. 
A continuación se presentarán los resultados obtenidos, de acuerdo a las comparaciones que fue posible realizar según datos extraídos de los estudios seleccionados por nuestra RS.

\section{Onda corta sola versus otra intervención sola}

Un estudio (58), con un $n=20$ pacientes, investigó la efectividad de la OC sola comparado con otra intervención sola, en pacientes con fractura de calcáneo.

Buzzard et al. (58), con un $\mathrm{n}=20$ pacientes, comparó la efectividad de la OCP versus crioterapia (Cryocuff), la dosis de OCP fue de $200 \mathrm{~ms}$ de duración de pulso, $26 \mathrm{~Hz}$ de frecuencia de pulso y $35 \mathrm{~W}$ de intensidad de salida, con una duración de 15 minutos; las sesiones se realizaron 2 veces al día, la duración total del tratamiento fue de 5 días, las medidas de resultado estudiadas fueron: rango de movimiento e inflamación del tobillo, el estudio no contempló seguimiento. Al analizar los resultados hubo un incremento significativo del ROM de dorsi-flexión y flexión-plantar de tobillo $\left(25^{\circ}\right.$ rango $\left.5-55^{\circ}, \mathrm{p}<0,001\right)$ y una reducción del edema $(1,36$ cm rango 0,3 - 5,2 cm, p < 0,001) en todos los pacientes comparado con los datos basales; sin embargo, al realizar la comparación entre los grupos, no hubo diferencia estadísticamente significativa en ninguna de las variables estudiadas.

TABLA III. CARACTERÍSTICAS DE LOS ARTÍCULOS INCLUIDOS SOBRE OSTEOARTRITIS DE RODILLA

\begin{tabular}{|c|c|c|c|c|}
\hline Autor/Año & $\begin{array}{l}\text { Condición/Método de } \\
\text { aleatorización }\end{array}$ & $\begin{array}{c}\text { Características de } \\
\text { pacientes }\end{array}$ & Intervención & $\begin{array}{c}\text { Seguimiento/Medidas } \\
\text { de resultado }\end{array}$ \\
\hline \multirow{9}{*}{ Akyol et al. (40) } & \multirow{5}{*}{$\begin{array}{l}\text { MDA: se realizó con } \\
\text { sobres y fue oculta } \\
\text { Pacientes con OA } \\
\text { rodilla bilateral (Dg } \\
\text { clínico y } \mathrm{Rx} \text { ) }\end{array}$} & & $\begin{array}{l}\text { Intervención: } 4 \\
\text { semanas }\end{array}$ & Seguimiento: 3 meses \\
\hline & & & $\begin{array}{l}\text { Grupo 1: OCC } 20 \\
\text { minutos, } 3 \text { veces }\end{array}$ & Medidas de resultado \\
\hline & & $\mathrm{n}=40$ pacientes & $\begin{array}{l}\text { (12 sesiones) más } \\
\text { ej. isocinético, } 10\end{array}$ & $\begin{array}{l}\text { Funcionalidad: } \\
\text { WOMAC y distancia }\end{array}$ \\
\hline & & Rango de edad: 42- & $\begin{array}{l}\text { rep. (Con/Con) en } \\
\text { velocidad angular de }\end{array}$ & de marcha 6 minutos \\
\hline & & 74 años & $\begin{array}{l}60^{\circ} / \mathrm{s}, 90^{\circ} / \mathrm{s}, 120^{\circ} / \mathrm{s} \\
150^{\circ} / \mathrm{s} \text { y } 180^{\circ} / \mathrm{s} \text { para }\end{array}$ & Dolor: EVA \\
\hline & \multirow{2}{*}{$\begin{array}{l}\text { Grupo 1: programa } \\
\text { de tratamiento } \\
\text { con OCC más ej. } \\
\text { isocinético }\end{array}$} & $\begin{array}{l}\text { Grupo 1: } \mathrm{n}=20 \\
\text { Edad: } 57,8 \text { años } \\
\text { (DS } 10,65 \text { ) }\end{array}$ & $\begin{array}{l}\text { flexores y extensores, } \\
10 \mathrm{~s} \text { de descanso } \\
\text { entre las diferentes }\end{array}$ & $\begin{array}{l}\text { Calidad de vida: con } \\
\text { subescala SF-36 }\end{array}$ \\
\hline & & Grupo 2: $\mathrm{n}=20$ & $\begin{array}{l}\text { modalidades y } 10 \mathrm{~min} \\
\text { de descanso por rodilla }\end{array}$ & $\begin{array}{l}\text { Fuerza muscular: } \\
\text { con dinamómetro }\end{array}$ \\
\hline & \multirow[t]{2}{*}{$\begin{array}{l}\text { Grupo 2: } \\
\text { intervención con } \\
\text { ejercicio isocinético }\end{array}$} & $\begin{array}{l}\text { Edad: } 56,60 \text { años } \\
\text { (DS 8,13) }\end{array}$ & $\begin{array}{l}\text { Grupo 2: } \\
\text { intervención de ej. }\end{array}$ & $\begin{array}{l}\text { isocinético } \\
\text { computarizado }\end{array}$ \\
\hline & & & $\begin{array}{l}\text { isocinético similar } \\
\text { al grupo anterior, } 12 \\
\text { sesiones, } 3 \text { veces a } \\
\text { la semana durante } 4 \\
\text { semanas }\end{array}$ & $\begin{array}{l}\text { Depresión: con BDI } \\
\text { (Beck Depression } \\
\text { Inventory) }\end{array}$ \\
\hline \multirow[b]{2}{*}{ Atamaz et al. (41) } & \multirow{2}{*}{$\begin{array}{l}M D A \text { : no se reporta } \\
\text { cómo se realizó la } \\
\text { aleatorización }\end{array}$} & $\mathrm{n}=85$ pacientes & $\begin{array}{l}\text { Intervención: grupo } 1 \\
\text { fue } 6 \text { meses; grupo } 2 \\
\text { fue } 3 \text { semanas }\end{array}$ & $\begin{array}{l}\text { Seguimiento: } 1,3,6, \\
9 \text { y } 12 \text { meses }\end{array}$ \\
\hline & & 18 hombres y 67 & Grupo 1: inyección & Medidas de resultado \\
\hline \multirow[t]{3}{*}{2006} & \multirow{3}{*}{$\begin{array}{l}\text { OA de rodilla por } \\
\text { (Dg clínico y Rx) } \\
\text { sintomáticos al } \\
\text { menos } 6 \text { meses }\end{array}$} & & $\begin{array}{l}\text { intraarticular con (HS) } \\
\text { y hylan (G-F 20), } 1\end{array}$ & DOM. anniómetra \\
\hline & & Rango de edad: 40- & vez por semana en las & RUM: goniometro \\
\hline & & 80 anos & $\begin{array}{l}3 \text { primeras semanas, } \\
\text { después } 1 \text { vez al mes } \\
\text { hasta el } 6^{\circ} \text { mes }\end{array}$ & Dolor: EVA \\
\hline
\end{tabular}


TABLA III (CONT.). CARACTERÍSTICAS DE LOS ARTÍCULOS INCLUIDOS SOBRE OSTEOARTRITIS DE RODILLA

\begin{tabular}{|c|c|c|c|c|}
\hline Autor/Año & $\begin{array}{l}\text { Condición/Método de } \\
\text { aleatorización }\end{array}$ & $\begin{array}{c}\text { Características de } \\
\text { pacientes }\end{array}$ & Intervención & $\begin{array}{c}\text { Seguimiento/Medidas } \\
\text { de resultado }\end{array}$ \\
\hline $\begin{array}{l}\text { Atamaz et al. (41) } \\
2006\end{array}$ & $\begin{array}{l}\text { Grupo 1: inyección } \\
\text { intraarticular con } \\
\text { hialunoridato de } \\
\text { sodio (HS) o hylan } \\
\text { G-F } 20 \\
\text { Grupo 2: programa } \\
\text { de tratamiento con } \\
\text { agentes físicos }\end{array}$ & $\begin{array}{l}\text { Grupo 2: } \\
\mathrm{n}=42 \\
\text { Edad: } 60,4 \text { años } \\
\text { (DS 9,3) }\end{array}$ & $\begin{array}{l}\text { Grupo 2: programa } \\
\text { de tto. con IR, OCP } \\
\text { y TIF, } 15 \text { sesiones, } 5 \\
\text { veces a la semana por } \\
3 \text { semanas }\end{array}$ & $\begin{array}{l}\text { Funcionalidad: con } \\
\text { WOMAC. Versión } \\
\text { corta del SF-36 y } \\
\text { tiempo de caminar } \\
\text { una distancia de } 15 \\
\text { metros }\end{array}$ \\
\hline \multirow{12}{*}{ Atamaz et al. (42) } & \multirow{2}{*}{$\begin{array}{l}M D A \text { : central con } \\
\text { números }\end{array}$} & $\mathrm{n}=203$ pacientes & & \multirow{5}{*}{$\begin{array}{l}\text { Seguimiento: } 6 \text { meses } \\
\text { Medidas de resultado } \\
\text { Dolor: EVA } \\
\text { y consumo de } \\
\text { analgésicos }\end{array}$} \\
\hline & & $\begin{array}{l}\text { Rango de edad: } \\
50-80 \text { años }\end{array}$ & $\begin{array}{l}\text { Intervención: } 5 \text { ve- } \\
\text { ces/semana, durante } 3 \\
\text { semanas }\end{array}$ & \\
\hline & $\begin{array}{l}\text { OA de rodilla grado } 2 \\
\text { o } 3(\mathrm{Rx}) \text {. Sintomático } \\
\text { al menos } 6 \text { meses }\end{array}$ & $\begin{array}{l}\text { Grupo } 1: \\
\mathrm{n}=37 \\
\text { Edad: } 60,7+6,5 \\
\text { Sexo: } 27 \text { mujeres y } \\
10 \text { hombres }\end{array}$ & $\begin{array}{l}\text { Grupo 1: } \\
\text { TENS apagado, pro- } \\
\text { grama de ej.: correr } \\
\text { durante 5-6 min, } \\
\text { elongaciones EEII, }\end{array}$ & \\
\hline & $\begin{array}{l}\text { Grupo 1: TENS } \\
\text { placebo (máquina } \\
\text { apagada), más pauta } \\
\text { de ejercicios y } \\
\text { educación }\end{array}$ & $\begin{array}{l}\text { Grupo } 2 \text { : } \\
\text { n }=37 \\
\text { Edad: } 61,9+6,9 \\
\text { Sexo: } 31 \text { mujeres y } 6 \\
\text { hombres }\end{array}$ & $\begin{array}{l}\text { ejercicios isométricos } \\
\text { de cuádriceps (10-15 } \\
\text { repeticiones con } 10 \mathrm{~s} \\
\text { de contracción y pau- } \\
\text { sa), ej. en domicilio } 3 \\
\text { veces/semana y edu- }\end{array}$ & \\
\hline & Grupo 2: TENS más & $\begin{array}{l}\text { Grupo 3: } \\
\mathrm{n}=35\end{array}$ & \multirow{4}{*}{$\begin{array}{l}\text { cacion para las AVD } \\
\text { Grupo 2: } \\
\text { TENS, Frec } 80 \mathrm{~Hz} \text {, } \\
\text { intensidad } 10-30 \mathrm{~mA} \text {, } \\
20 \text { min. Programa de } \\
\text { ej. y educación simi- } \\
\text { lar al grupo anterior }\end{array}$} & \\
\hline & $\begin{array}{l}\text { programa de ej. y } \\
\text { educación }\end{array}$ & Edad: $61.3+7.8$ & & \multirow{3}{*}{$\begin{array}{l}\text { Funcionalidad: } \\
\text { tiempo de caminar, } \\
\text { WOMAC, } \\
\text { Nottingham Health } \\
\text { Profile (NHP) }\end{array}$} \\
\hline & & hombres & & \\
\hline & $\begin{array}{l}\text { interferencial }(\mathrm{CI}) \\
\text { placebo más pauta de }\end{array}$ & $\begin{array}{l}\text { Grupo 4: } \\
\mathrm{n}=31\end{array}$ & & \\
\hline & $\begin{array}{l}\text { Grupo 4: CI más ej. y } \\
\text { educación }\end{array}$ & $\begin{array}{l}\text { Edad: } 62,0+7,9 \\
\text { Sexo: } 27 \text { mujeres y } 4 \\
\text { hombres }\end{array}$ & \multirow{2}{*}{$\begin{array}{l}\text { Grupo 3: } \\
\text { CI apagada, progra- } \\
\text { ma de ej. y educación } \\
\text { similar al grupo an- } \\
\text { terior }\end{array}$} & \multirow[t]{4}{*}{$\begin{array}{l}\text { Rango de } \\
\text { movimiento: } \\
\text { goniómetro }\end{array}$} \\
\hline & Grupo 5: OCC & $\begin{array}{l}\text { Grupo } 5: \\
\mathrm{n}=32\end{array}$ & & \\
\hline & $\begin{array}{l}\text { placebo (maquina } \\
\text { apagada) más pauta } \\
\text { de ej. y educación. }\end{array}$ & $\begin{array}{l}\text { Edad: } 61,4+8.2 \\
\text { Sexo: } 27 \text { mujeres y } 5 \\
\text { hombres }\end{array}$ & \multirow{2}{*}{$\begin{array}{l}\text { Grupo 4: } \\
\text { CI, AMF } 100 \mathrm{~Hz} \\
\text { generados por onda } \\
\text { sinusoidal de } 4 \mathrm{kHz} \text {, } \\
20 \text { min. Programa de } \\
\text { ej. y educación simi- } \\
\text { lar al grupo anterior }\end{array}$} & \\
\hline & $\begin{array}{l}\text { Grupo 6: OCC más } \\
\text { ej. y educación }\end{array}$ & $\begin{array}{l}\text { Grupo 6: } \\
\mathrm{n}=31 \\
\text { Edad: } 61,6+7,4 \\
\text { Sexo: } 27 \text { mujeres y } 4 \\
\text { hombres }\end{array}$ & & \\
\hline
\end{tabular}


TABLA III (CONT.). CARACTERÍSTICAS DE LOS ARTÍCULOS INCLUIDOS SOBRE OSTEOARTRITIS DE RODILLA

\begin{tabular}{cccc}
\hline Autor/Año & $\begin{array}{c}\text { Condición/Método de } \\
\text { aleatorización }\end{array}$ & $\begin{array}{c}\text { Características de } \\
\text { pacientes }\end{array}$ & Intervención \\
\hline
\end{tabular}

Grupo 5:

OCC apagada, pro-

grama de ej. y educa-

ción similar al grupo

Atamaz et al. (42)

anterior

2012

Grupo 6:

OCC, intensidad de entrada $300 \mathrm{~W}$ y 3,2

$\mathrm{W}$ de salida, 5 veces/ semana. Programa de ej. y educación similar al grupo anterior

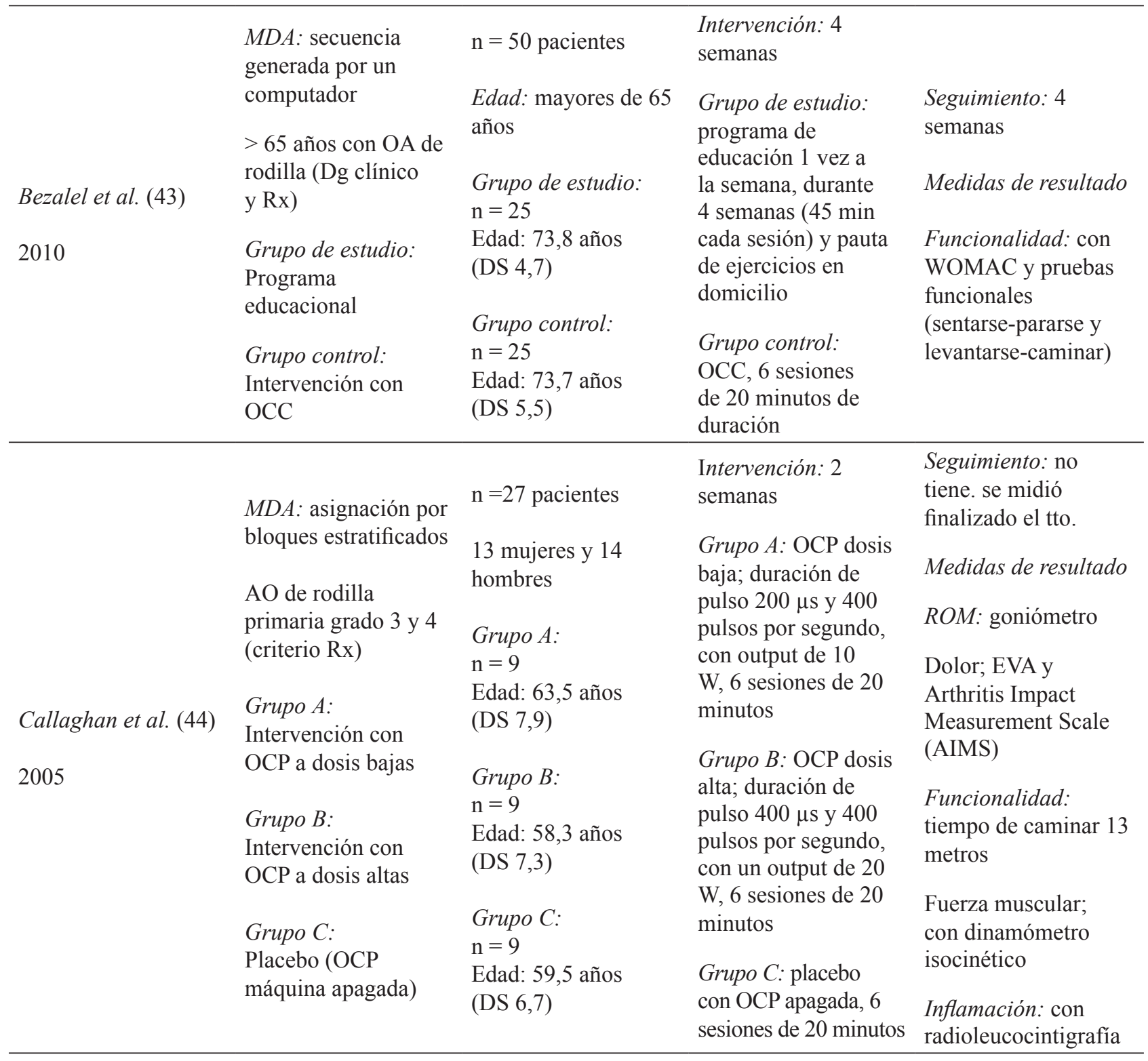


TABLA III (CONT.). CARACTERÍSTICAS DE LOS ARTÍCULOS INCLUIDOS SOBRE OSTEOARTRITIS DE RODILLA

\begin{tabular}{|c|c|c|c|c|}
\hline Autor/Año & $\begin{array}{l}\text { Condición/Método de } \\
\text { aleatorización }\end{array}$ & $\begin{array}{c}\text { Características de } \\
\text { pacientes }\end{array}$ & Intervención & $\begin{array}{c}\text { Seguimiento/Medidas } \\
\text { de resultado }\end{array}$ \\
\hline \multirow{9}{*}{ Cantarini et al. (45) } & & & $\begin{array}{l}\text { Intervención: } 3 \\
\text { semanas }\end{array}$ & \\
\hline & $\begin{array}{l}M D A: \text { no se reporta } \\
\text { cómo se realizó la } \\
\text { aleatorización }\end{array}$ & $\mathrm{n}=74$ pacientes & \multirow{3}{*}{$\begin{array}{l}\text { Grupo 1: programa } \\
\text { de tratamiento con } \\
\text { compresas de barro, } \\
\text { por } 20 \text { min a } 45^{\circ} \mathrm{C}, \\
\text { y baños de aguas } \\
\text { minerales, por } 15 \\
\text { minutos a } 38^{\circ} \mathrm{C}, 15 \\
\text { sesiones }\end{array}$} & $\begin{array}{l}\text { Seguimiento: } 12 \\
\text { semanas }\end{array}$ \\
\hline & OA de rodilla & Edad: 46-84 años & & Dolor con EVA \\
\hline & $\begin{array}{l}\text { primaria (Dg clínico } \\
\text { y Rx grados } 1 \text { a } \\
\text { 3) sintomáticos al } \\
\text { menos } 12 \text { meses }\end{array}$ & $\begin{array}{l}\text { Grupo 1: } \\
\mathrm{n}=30 \\
\text { Edad: } 65,6 \text { años } \\
\text { (DS } 10,88 \text { ) }\end{array}$ & & $\begin{array}{l}\text { Funcionalidad } \\
\text { con cuestionario } \\
\text { de Lequesne } \\
\text { Algofunctional }\end{array}$ \\
\hline & Grupo 1: programa & Grupo 2: & \multirow{3}{*}{$\begin{array}{l}\text { Grupo 2: } \\
\text { intervención con } \\
\text { OCC, } 15 \text { min, } 3 \\
\text { veces/ semana, } 10 \\
\text { sesiones }\end{array}$} & Questionnaire \\
\hline & SPA & $\begin{array}{l}\mathrm{n}=24 \\
\text { Edad: } 60,8 \text { años }\end{array}$ & & Calidad de vida: \\
\hline & Grupo 2: programa & (DS 8,10) & & $\begin{array}{l}\text { Arthritis Impact } \\
\text { Measurement Scale }\end{array}$ \\
\hline & $\begin{array}{l}\text { de tratamiento con } \\
\text { OCC }\end{array}$ & Grupo 3: & \multirow[b]{2}{*}{$\begin{array}{l}\text { Grupo 3: grupo } \\
\text { control manteniendo } \\
\text { los cuidados } \\
\text { ambulatorios y de } \\
\text { rutina (tratamiento } \\
\text { farmacológico y no } \\
\text { farmacológico) }\end{array}$} & (AIMS) \\
\hline & $\begin{array}{l}\text { Grupo 3: continúa } \\
\text { con su rutina } \\
\text { ambulatoria }\end{array}$ & $\begin{array}{l}\mathrm{n}=20 \\
\text { Edad: 65,8 años } \\
\text { (DS 6,67) }\end{array}$ & & $\begin{array}{l}\text { Consumo de } \\
\text { analgésico: } \mathrm{n}^{\circ} \text { de } \\
\text { tabletas consumidas }\end{array}$ \\
\hline \multirow{11}{*}{ Cetin et al. (46) } & $\begin{array}{l}M D A: \text { no se reporta } \\
\text { cómo se realizó la }\end{array}$ & $\mathrm{n}=100$ pacientes & \multirow{11}{*}{$\begin{array}{l}\text { Intervención: } 8 \\
\text { semanas } \\
\text { Grupo 1: programa } \\
\text { de tratamiento } \\
\text { de } 24 \text { sesiones, } \\
3 \text { veces/ semana, } \\
\text { con OCC, } 15 \text { min, } \\
\text { compresas calientes } \\
\text { y ej. isocinético, } 5 \\
\text { rep. (Con/Con) en } \\
\text { velocidad angular } \\
\text { de } 60^{\circ} / \mathrm{s}, 120^{\circ} / \mathrm{s}, \\
180^{\circ} / \mathrm{s} \text { para flexores } \\
\text { y extensores, } 20 \mathrm{~s} \\
\text { de descanso entre } \\
\text { las diferentes } \\
\text { modalidades y } \\
60 \text { s de descanso por } \\
\text { rodilla }\end{array}$} & $\begin{array}{l}\text { Seguimiento: no } \\
\text { tiene, se midió }\end{array}$ \\
\hline & aleatorizacion & $\begin{array}{l}\text { Edad: } 59,82 \text { años } \\
\text { (DS } 9,05 \text { ) }\end{array}$ & & finalizado el tto. \\
\hline & $\begin{array}{l}\text { Pacientes con OA de } \\
\text { rodilla bilateral (Dg }\end{array}$ & & & Medidas de resultado \\
\hline & clínico y radiológico) & $\begin{array}{l}\text { Grupo 1: } \\
\mathrm{n}=20\end{array}$ & & Dolor: EVA \\
\hline & $\begin{array}{l}\text { Grupo 1: programa } \\
\text { de tratamiento con }\end{array}$ & $\begin{array}{l}\text { Edad: } 59,75 \text { años } \\
\text { (DS } 11,63 \text { ) }\end{array}$ & & Funcionalidad: \\
\hline & OCC, compresas & Grupo 2: & & Algofunctional \\
\hline & isocinético & $\begin{array}{l}\mathrm{n}=20 \\
\text { Edad } 6185 \text { años }\end{array}$ & & $\begin{array}{l}\text { Questionnaire y } \\
\text { tiempo de caminar } 50\end{array}$ \\
\hline & Grupo 2: programa & (DS 8,64) & & metros/segundo \\
\hline & $\begin{array}{l}\text { de tratamiento con } \\
\text { TENS, compresas } \\
\text { calientes más ej. } \\
\text { isocinético }\end{array}$ & $\begin{array}{l}\text { Grupo 3: } \\
\mathrm{n}=20 \\
\text { Edad: } 57,60 \text { años } \\
\text { (DS 7,33) }\end{array}$ & & $\begin{array}{l}\text { Discapacidad: Index } \\
\text { of severity for knee } \\
\text { osteoarthritis (ISK) }\end{array}$ \\
\hline & Grupo 3: programa & & & Conformidad \\
\hline & $\begin{array}{l}\text { de tratamiento con } \\
\text { US, compresas } \\
\text { calientes más ej. } \\
\text { isocinético }\end{array}$ & $\begin{array}{l}\text { Grupo 4: } \\
\mathrm{n}=20 \\
\text { Edad: } 61,05 \text { años } \\
(\mathrm{DS} 8,26)\end{array}$ & & $\begin{array}{l}\text { Fuerza: dinamómetro } \\
\text { isocinético } \\
\text { computarizado }\end{array}$ \\
\hline
\end{tabular}


TABLA III (CONT.). CARACTERÍSTICAS DE LOS ARTÍCULOS INCLUIDOS SOBRE OSTEOARTRITIS DE RODILLA

\begin{tabular}{|c|c|c|c|c|}
\hline Autor/Año & $\begin{array}{c}\text { Condición/Método de } \\
\text { aleatorización }\end{array}$ & $\begin{array}{c}\text { Caracteristicas de } \\
\text { pacientes }\end{array}$ & Intervención & $\begin{array}{c}\text { Seguimiento/Medidas } \\
\text { de resultado }\end{array}$ \\
\hline $\begin{array}{l}\text { Cetin et al. (46) } \\
2008\end{array}$ & $\begin{array}{l}\text { Grupo 4: programa } \\
\text { de tratamiento con } \\
\text { compresas calientes } \\
\text { más ej. isocinético } \\
\text { Grupo 5: } \\
\text { intervención con ej. } \\
\text { isocinético }\end{array}$ & $\begin{array}{l}\text { Grupo } 5: \\
\mathrm{n}=20 \\
\text { Edad: } 58,85 \text { años (DS } \\
9,08)\end{array}$ & $\begin{array}{l}\text { Grupo 2: programa } \\
\text { de tratamiento de } 24 \\
\text { sesiones, } 3 \text { veces/ } \\
\text { semana, con TENS, } \\
20 \text { min, frec. } 60-100 \\
\text { Hz, duración de pulso } \\
60 \text { msec, compresas } \\
\text { calientes y ej. } \\
\text { isocinético (similar al } \\
\text { grupo anterior) } \\
\text { Grupo } 3 \text { : programa } \\
\text { de tratamiento de } 24 \\
\text { sesiones, } 3 \text { veces/ } \\
\text { semana, con US, } 10 \\
\text { min, frec. de } 1 \mathrm{MHz}, \\
\text { intensidad de } 1,5 \\
\text { W/cm2, compresas } \\
\text { calientes y ej. } \\
\text { isocinético (similar al } \\
\text { grupo anterior) } \\
\text { Grupo } 4 \text { : programa } \\
\text { de tratamiento } \\
\text { de } 24 \text { sesiones, } 3 \\
\text { veces/ semana, con } \\
\text { compresas calientes } \\
\text { y ej. isocinético } \\
\text { (similar al grupo } \\
\text { anterior) } \\
\text { Grupo } 5 \text { : } \\
\text { intervención de } 24 \\
\text { sesiones, } 3 \text { veces/ } \\
\text { semana, con ej. } \\
\text { isocinético (similar al } \\
\text { grupo anterior) }\end{array}$ & \\
\hline
\end{tabular}

$M D A$ : no se reporta cómo se realizó la aleatorización

Pacientes $>40$ años

Fukuda et al. (47) con OA de rodilla primaria grado II y III (Dg clínico y $\mathrm{Rx}$ ), sintomáticos por más de 3 meses

Grupo control: sin intervención $\mathrm{n}=84$ pacientes

mujeres

Intervención: 3

semanas

Edad: mayores de 40 Grupo control: $\sin$ años

Grupo control: Grupo placebo:

$\mathrm{n}=18$

Edad: 60 años

(DS 10) intervención

OCP apagada, 19 min, 3 veces/ semana

Seguimiento: no tiene, se midió finalizado el tto.

Medidas de resultado

Dolor: EVA 
TABLA III (CONT.). CARACTERÍSTICAS DE LOS ARTÍCULOS INCLUIDOS SOBRE OSTEOARTRITIS DE RODILLA

\begin{tabular}{|c|c|c|c|c|}
\hline Autor/Año & $\begin{array}{c}\text { Condición/Método de } \\
\text { aleatorización }\end{array}$ & $\begin{array}{c}\text { Características de } \\
\text { pacientes }\end{array}$ & Intervención & $\begin{array}{c}\text { Seguimiento/Medidas } \\
\text { de resultado }\end{array}$ \\
\hline \multirow{6}{*}{ Fukuda et al. (47) } & & & $\begin{array}{l}\text { Grupo 1: OCP, } \\
\text { potencia máxima }\end{array}$ & \multirow{6}{*}{$\begin{array}{l}\text { Funcionalidad: } \\
\text { Lequesne } \\
\text { Algofunctional } \\
\text { Questionnaire y } \\
\text { Lysholm Scale }\end{array}$} \\
\hline & & Grupo placebo: & & \\
\hline & $\begin{array}{l}\text { Grupo placebo: } \\
\text { placebo (máquina } \\
\text { apagada) }\end{array}$ & $\begin{array}{l}\mathrm{n}=20 \\
\text { Edad: } 57 \text { años } \\
\text { (DS 09) }\end{array}$ & $\begin{array}{l}\text { potencia media } 14,5 \\
\mathrm{~W}, 38 \text { min con } 33 \mathrm{KJ}\end{array}$ & \\
\hline & $\begin{array}{l}\text { Grupo 1: } \\
\text { intervención }\end{array}$ & $\begin{array}{l}\text { Grupo 1: } \\
\mathrm{n}=24\end{array}$ & $\begin{array}{l}\text { energía total, } 3 \text { veces/ } \\
\text { semana, } 9 \text { sesiones }\end{array}$ & \\
\hline & OCP a dosis altas & $\begin{array}{l}\text { Edad: } 63 \text { años } \\
\text { (DS 09) }\end{array}$ & \multirow{2}{*}{$\begin{array}{l}\text { Grupo 2: OCP, } \\
\text { potencia máxima } \\
250 \mathrm{~W} \text {, duración de } \\
\text { pulso } 400 \mathrm{us,} \mathrm{frec.} \\
\text { de pulso } 145 \mathrm{~Hz}, \\
\text { potencia media } 14,5 \\
\mathrm{~W}, 19 \text { min con } 17 \mathrm{KJ} \\
\text { energía total, } 3 \text { veces/ } \\
\text { semana, } 9 \text { sesiones }\end{array}$} & \\
\hline & $\begin{array}{l}\text { Grupo 2: } \\
\text { intervención con } \\
\text { OCP a dosis bajas }\end{array}$ & $\begin{array}{l}\text { Grupo 2: } \\
\mathrm{n}=22 \\
\text { Edad: } 62 \text { años } \\
\text { (DS 08) }\end{array}$ & & \\
\hline \multirow{17}{*}{ Fukuda et al. (48) } & & & $\begin{array}{l}\text { Intervención: } 3 \\
\text { semanas }\end{array}$ & \multirow{6}{*}{$\begin{array}{l}\text { Seguimiento: } 12 \\
\text { meses }\end{array}$} \\
\hline & $\begin{array}{l}M D A \text { : central y fue } \\
\text { oculta con sobres }\end{array}$ & $\begin{array}{l}\mathrm{n}=121 \text { pacientes } \\
\text { mujeres }\end{array}$ & $\begin{array}{l}\text { Grupo control: } \\
\text { sin intervención }\end{array}$ & \\
\hline & opacos y sellados & $\begin{array}{l}\text { Edad media: } 60 \text { años } \\
\text { (SD 9) }\end{array}$ & \multirow{3}{*}{$\begin{array}{l}\text { Grupo placebo: } \\
\text { OCP apagada, } 19 \\
\text { min, } 3 \text { veces/semana } \\
9 \text { sesiones }\end{array}$} & \\
\hline & Pacientes $>40$ años & & & \\
\hline & $\begin{array}{l}\text { con OA de rodilla } \\
\text { primaria grado II y }\end{array}$ & $\begin{array}{l}\text { Grupo control: } \\
\mathrm{n}=35\end{array}$ & & \\
\hline & $\begin{array}{l}\text { III (Dg clínico y Rx) } \\
\text { sintomáticos por }\end{array}$ & Edad: 61,0 años & Grupo bajas dosis & \\
\hline & más de 3 meses & & potencia máxima de & Medidas de resultado \\
\hline & & Grupo placebo: & $250 \mathrm{~W}$, duración de & \multirow{3}{*}{$\begin{array}{l}\text { Dolor: escala } \\
\text { numérica de } 11 \\
\text { puntos. }\end{array}$} \\
\hline & $\begin{array}{l}\text { Grupo control: sin } \\
\text { intervención }\end{array}$ & $\begin{array}{l}\mathrm{n}=23 \\
\text { Edad. } 570 \text { años }\end{array}$ & $\begin{array}{l}\text { pulso de } 400 \mu \mathrm{s} \text {, frec. } \\
\text { de pulso } 145 \mathrm{~Hz} \text {. }\end{array}$ & \\
\hline & & $(\mathrm{DS} 9,0)$ & potencia media 14,5 & \\
\hline & $\begin{array}{l}\text { Grupo placebo: } \\
\text { placebo (máquina } \\
\text { apagada) }\end{array}$ & $\begin{array}{l}\text { Grupo bajas dosis } \\
\text { OCP: }\end{array}$ & $\begin{array}{l}\mathrm{W}, 19 \text { min con } 17 \mathrm{KJ} \\
\text { energía total, } 3 \text { veces/ } \\
\text { semana, } 9 \text { sesiones }\end{array}$ & \multirow{7}{*}{$\begin{array}{l}\text { Funcionalidad: Knee } \\
\text { and Osteoarthritis } \\
\text { Outcome Score } \\
\text { (KOOS) }\end{array}$} \\
\hline & Grupo 1: & $\begin{array}{l}\mathrm{n}=32 \\
\text { Edad: } 62,0 \text { años }\end{array}$ & $\begin{array}{l}\text { Grupo altas dosis } \\
\text { OCP: }\end{array}$ & \\
\hline & $\begin{array}{l}\text { intervencion con } \\
\text { OCP a dosis bajas }\end{array}$ & & OCP con potencia & \\
\hline & & Grupo altas dosis & duración de pulso & \\
\hline & $\begin{array}{l}\text { Grupo 2: } \\
\text { interyencón }\end{array}$ & OCP: & $400 \mu \mathrm{s}$, frec. de pulso & \\
\hline & OCP a dosis altas & Edad: 63,0 años & $145 \mathrm{~Hz}$, potencia & \\
\hline & & $(\mathrm{DS} 9,0)$ & $\begin{array}{l}\text { min con } 33 \mathrm{KJ} \\
\text { energía total, } 3 \text { veces/ } \\
\text { semana, } 9 \text { sesiones }\end{array}$ & \\
\hline
\end{tabular}


TABLA III (CONT.). CARACTERÍSTICAS DE LOS ARTÍCULOS INCLUIDOS SOBRE OSTEOARTRITIS DE RODILLA

\begin{tabular}{|c|c|c|c|c|}
\hline Autor/Año & $\begin{array}{l}\text { Condición/Método de } \\
\text { aleatorización }\end{array}$ & $\begin{array}{c}\text { Características de } \\
\text { pacientes }\end{array}$ & Intervención & $\begin{array}{c}\text { Seguimiento/Medidas } \\
\text { de resultado }\end{array}$ \\
\hline \multirow{5}{*}{ Jan et al. (49) } & $\begin{array}{l}M D A: \text { se realizó por } \\
\text { decisión propia de los } \\
\text { pacientes a qué grupo } \\
\text { asistían }\end{array}$ & $\begin{array}{l}\mathrm{n}=30 \text { pacientes } \\
\text { (44 rodillas) } \\
6 \text { hombres y } 24 \\
\text { mujeres }\end{array}$ & $\begin{array}{l}\text { Intervención: } 8 \\
\text { semanas }\end{array}$ & \multirow[b]{2}{*}{$\begin{array}{l}\text { Seguimiento: } 3 \\
\text { semanas } \\
\text { Medidas de resultado }\end{array}$} \\
\hline & $\begin{array}{l}\text { Pacientes con OA } \\
\text { grados } 1,2 \text { y } 3 \\
\text { (criterio Rx) }\end{array}$ & $\begin{array}{l}\text { Grupo OCC: } \\
\mathrm{n}=11 / 14 \text { rodillas } \\
\text { Edad: } 62,7 \text { años }\end{array}$ & $\begin{array}{l}\text { Grupo OCC: } \\
\text { OCC por } 20 \text { min, } 3-5 \\
\text { veces/semana, con un } \\
\text { total de } 30 \text { sesiones }\end{array}$ & \\
\hline & $\begin{array}{l}\text { Grupo 1: } \\
\text { intervención con } \\
\text { OCC }\end{array}$ & Grupo OCC y AINEs: & $\begin{array}{l}\text { Grupo OCC y AINEs: } \\
\text { OCC por } 20 \mathrm{~min}, 3-5\end{array}$ & Dolor: EVA \\
\hline & $\begin{array}{l}\text { Grupo 2: programa } \\
\text { de tratamiento con }\end{array}$ & $\begin{array}{l}\text { Edad: } 68,4 \text { años } \\
\text { (DS 9,2) }\end{array}$ & $\begin{array}{l}\text { total de } 30 \text { sesiones } \\
\text { más AINEs }\end{array}$ & \multirow[t]{2}{*}{$\begin{array}{l}\text { Inflamación: } \\
\text { ultrasonografía }\end{array}$} \\
\hline & $\begin{array}{l}\text { Grupo 3: sin } \\
\text { intervención }\end{array}$ & $\begin{array}{l}\text { Grupo control: } \\
\mathrm{n}=9 / 16 \text { rodillas } \\
\text { Edad: } 66,0 \text { años } \\
\text { (DS 6,2) }\end{array}$ & $\begin{array}{l}\text { Grupo control: } \sin \\
\text { intervención }\end{array}$ & \\
\hline
\end{tabular}

Intervención: 3

semanas

Laufer et al. (50)

$M D A$ : terapeutas determinaban la asignación a los grupos

Pacientes $>65$ años con OA de rodilla primaria grado II y III (Dg clínico y Rx) sintomáticos por más de 3 meses

2004
Grupo altas dosis: intervención con OCP a dosis altas

Grupo bajas dosis: intervención con OCP a dosis bajas

Grupo placebo: placebo con máquina apagada

\section{Grupo altas dosis}

$\mathrm{n}=103$ pacientes

Mayores de 65 años

Edad media 73,7 años (DS 6,6)

Grupo alta OCP: $\mathrm{n}=37$

Edad: 72,66 años (DS 6,36)

Grupo baja OCP: $\mathrm{n}=41$

Edad: 74,79 años

(DS 6,58)

Grupo placebo: $\mathrm{n}=37$

Edad: 73,33 años (DS 6,91)
$O C P$ :

OCP, duración de pulso de $300 \mu \mathrm{s}$, frec. de pulso de $300 \mathrm{~Hz}$, potencia máxima de $200 \mathrm{~W}$, potencia media de $18 \mathrm{~W}, 20$ min, 3 veces/semana, 9 sesiones

Grupo bajas dosis $O C P$ :

OCP, duración de pulso de $82 \mu \mathrm{s}$, frec. de pulso de $110 \mathrm{~Hz}$, potencia máxima de $200 \mathrm{~W}$, potencia media de 1,8 W, 20 min, 3 veces/semana, 9 sesiones

Grupo placebo: OC apagada, 20 minutos, 3 veces/ semana, 9 sesiones
Seguimiento: 3 meses

Medidas de resultado

Funcionalidad: WOMAC y (TGUG, 3 minutos de caminar, subir y bajar escaleras) 
TABLA III (CONT.). CARACTERÍSTICAS DE LOS ARTÍCULOS INCLUIDOS SOBRE OSTEOARTRITIS DE RODILLA

\begin{tabular}{|c|c|c|c|c|}
\hline Autor/Año & $\begin{array}{l}\text { Condición/Método de } \\
\text { aleatorización }\end{array}$ & $\begin{array}{c}\text { Características de } \\
\text { pacientes }\end{array}$ & Intervención & $\begin{array}{c}\text { Seguimiento/Medidas } \\
\text { de resultado }\end{array}$ \\
\hline \multirow{7}{*}{ Ovanessian et al. (51) } & & & $\begin{array}{l}\text { Intervención: } 3 \\
\text { semanas }\end{array}$ & \\
\hline & $\begin{array}{l}\text { MDA: no se reporta } \\
\text { cómo se realizó la } \\
\text { aleatorización }\end{array}$ & $\begin{array}{l}\mathrm{n}=42 \text { pacientes } \\
\text { mujeres }\end{array}$ & $\begin{array}{l}\text { Grupo control: sin } \\
\text { intervención }\end{array}$ & \\
\hline & $\begin{array}{l}\text { Pacientes }>40 \\
\text { años con OA de }\end{array}$ & $\begin{array}{l}\text { Edad: mayores de } 40 \\
\text { años }\end{array}$ & $\begin{array}{l}\text { Grupo 1: } \\
\text { OCP, potencia }\end{array}$ & $\begin{array}{l}\text { Seguimiento: no } \\
\text { tiene, se midió } \\
\text { finalizado el tto. }\end{array}$ \\
\hline & $\begin{array}{l}\text { rodilla grado II y III } \\
\text { (Dg clínico y Rx) } \\
\text { sintomáticos por } \\
\text { más de } 3 \text { meses }\end{array}$ & $\begin{array}{l}\text { Grupo control: } \\
\mathrm{n}=14 \\
\text { Edad: } 56 \text { años } \\
\text { (DS 17) }\end{array}$ & $\begin{array}{l}\text { máxima de } 250 \mathrm{~W} \text {, } \\
\text { duración de pulso } \\
\text { de } 400 \mu \mathrm{s} \text {, potencia } \\
\text { media de } 14,5 \mathrm{~W}, 33 \\
\text { KJ de energía total, }\end{array}$ & $\begin{array}{l}\text { Medidas de resultado } \\
\text { Dolor: EVA }\end{array}$ \\
\hline & $\begin{array}{l}\text { Grupo control: sin } \\
\text { intervención }\end{array}$ & $\begin{array}{l}\text { Grupo 1: } \\
\mathrm{N}=14\end{array}$ & $\begin{array}{l}38 \text { min, } 3 \text { veces/ } \\
\text { semana, } 9 \text { sesiones }\end{array}$ & $\begin{array}{l}\text { Funcionalidad: Knee } \\
\text { and Osteoarthritis }\end{array}$ \\
\hline & Grupo 1: intervención & $\begin{array}{l}\text { Edad: } 68 \text { años } \\
\text { (DS 14) }\end{array}$ & $\begin{array}{l}\text { Grupo 2: } \\
\text { OCP, potencia }\end{array}$ & $\begin{array}{l}\text { Outcome Score } \\
\text { (KOOS) }\end{array}$ \\
\hline & $\begin{array}{l}\text { Grupo 2: intervención } \\
\text { con OCP a dosis } \\
\text { bajas }\end{array}$ & $\begin{array}{l}\text { Grupo 2: } \\
\mathrm{n}=14 \\
\text { Edad: } 71 \text { años } \\
\text { (DS 8) }\end{array}$ & $\begin{array}{l}\text { máxima de } 250 \mathrm{~W} \text {, } \\
\text { duración de pulso } \\
\text { de } 400 \mu \mathrm{s} \text {, potencia } \\
\text { media de } 14,5 \mathrm{~W}, 17 \\
\text { KJ de energía total, } \\
19 \text { min, } 3 \text { veces/ } \\
\text { semana, } 9 \text { sesiones }\end{array}$ & ROM: goniómetro \\
\hline \multirow{8}{*}{$\begin{array}{l}\text { Rattanachaiyanont et } \\
\text { al. (52) }\end{array}$} & $\begin{array}{l}\text { MDA: se realizó } \\
\text { con una tabla de } \\
\text { números aleatorios y }\end{array}$ & $\mathrm{n}=113$ pacientes & $\begin{array}{l}\text { Intervención: } 3 \\
\text { semanas }\end{array}$ & $\begin{array}{l}\text { Seguimiento: } 3 \\
\text { semanas }\end{array}$ \\
\hline & fue oculta con sobres & mujeres & Grupo control: & Medidas de resultado \\
\hline & Pacientes con OA de & Edad: $50-85$ años & & $\begin{array}{l}\text { Funcionalidad: } \\
\text { WOMAC y (caminar }\end{array}$ \\
\hline & $\begin{array}{l}\text { rodilla primaria } \\
\text { (Dg clínico) }\end{array}$ & $\begin{array}{l}\text { Grupo control: } \\
\mathrm{n}=60\end{array}$ & $\begin{array}{l}\text { protección articular } \\
\text { más OC apagada, } 20\end{array}$ & $\begin{array}{l}100 \text { metros y subir- } \\
\text { bajar escaleras) }\end{array}$ \\
\hline & Grupo control: & $\begin{array}{l}\text { Edad: } 62,48 \text { años } \\
\text { (DS 8,47) }\end{array}$ & $\begin{array}{l}\text { min, } 3 \text { veces/semana, } \\
9 \text { sesiones }\end{array}$ & Evaluación global \\
\hline & $\begin{array}{l}\text { programa de ej. más } \\
\text { intervención placebo } \\
\text { (OC apagada) }\end{array}$ & $\begin{array}{l}\text { Grupo tratamiento: } \\
n=53\end{array}$ & $\begin{array}{l}\text { Grupo tratamiento: } \\
\text { similar programa de }\end{array}$ & Índice de satisfacción \\
\hline & Grupo tratamiento: & $\begin{array}{l}\text { Edad: 63,32 años } \\
\text { (DS 7,61) }\end{array}$ & $\begin{array}{l}\text { ej. más OCC, Input } \\
300 \mathrm{~W} \text {, Output } 3,2\end{array}$ & $\begin{array}{l}\text { Consumo de } \\
\text { analgésicos }\end{array}$ \\
\hline & $\begin{array}{l}\text { programa de ej. más } \\
\text { OCC. }\end{array}$ & & semana, 9 sesiones & $\begin{array}{l}\text { Satisfacción de los } \\
\text { ejercicios }\end{array}$ \\
\hline \multirow[t]{2}{*}{ Shakoor et al. (53) } & $\begin{array}{l}M D A: \text { no se reporta } \\
\text { cómo se realizó la } \\
\text { aleatorización }\end{array}$ & & \multirow{2}{*}{$\begin{array}{l}\text { Intervención: } 6 \\
\text { semanas }\end{array}$} & $\begin{array}{l}\text { Seguimiento: no } \\
\text { tiene, se midió }\end{array}$ \\
\hline & $\begin{array}{l}\text { Pacientes con OA de } \\
\text { rodilla (Dg clínico) }\end{array}$ & $\begin{array}{l}96 \text { hombres y } 66 \\
\text { mujeres }\end{array}$ & & Medidas de resultado \\
\hline
\end{tabular}


TABLA III (CONT.). CARACTERÍSTICAS DE LOS ARTÍCULOS INCLUIDOS SOBRE OSTEOARTRITIS DE RODILLA

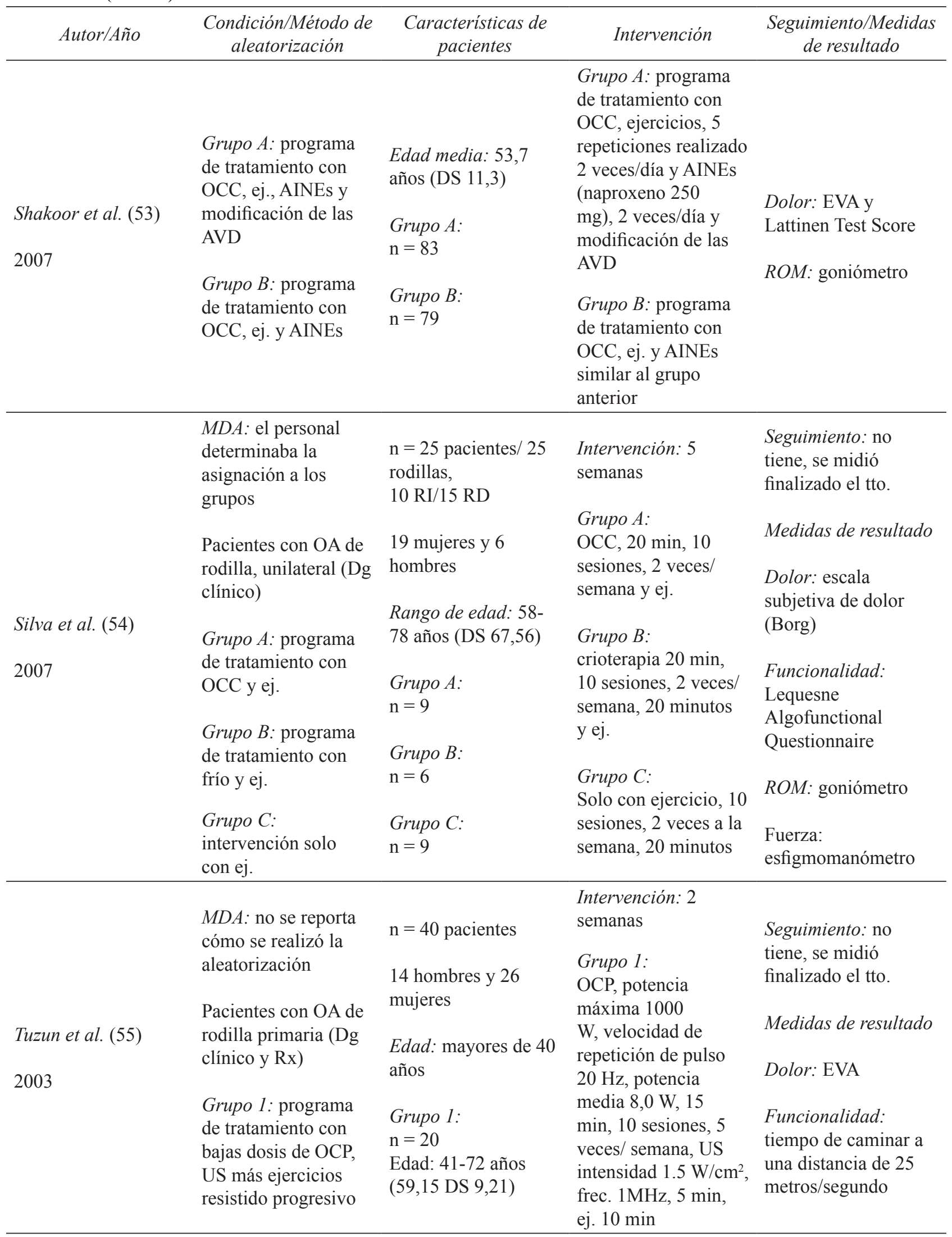


TABLA III (CONT.). CARACTERÍSTICAS DE LOS ARTÍCULOS INCLUIDOS SOBRE OSTEOARTRITIS DE RODILLA

\begin{tabular}{|c|c|c|c|c|}
\hline Autor/Año & $\begin{array}{l}\text { Condición/Método de } \\
\text { aleatorización }\end{array}$ & $\begin{array}{c}\text { Características de } \\
\text { pacientes }\end{array}$ & Intervención & $\begin{array}{c}\text { Seguimiento/Medidas } \\
\text { de resultado }\end{array}$ \\
\hline $\begin{array}{l}\text { Tuzun et al. (55) } \\
2003\end{array}$ & $\begin{array}{l}\text { Grupo 2: programa } \\
\text { de tratamiento con } \\
\text { altas dosis de OCP, } \\
\text { US más ejercicios } \\
\text { resistido progresivo }\end{array}$ & $\begin{array}{l}\text { Grupo 2: } \\
\text { n = 20 } \\
\text { Edad: } 43-72 \text { años } \\
(58,15 \text { DS } 7,21)\end{array}$ & $\begin{array}{l}\text { Grupo 2: } \\
\text { OCP, potencia } \\
\text { máxima } 600 \mathrm{~W}, \\
\text { velocidad de } \\
\text { repetición de pulso } \\
110 \mathrm{~Hz} \text {, potencia } \\
\text { media } 26,4 \mathrm{~W}, 10 \\
\text { sesiones, } 5 \text { veces/ } \\
\text { semana, } 15 \text { min, US } \\
\text { y ej. (similar al grupo } \\
\text { anterior) }\end{array}$ & $\begin{array}{l}\text { ROM: goniómetro } \\
\text { Fuerza: técnicas } \\
\text { DeLorme }\end{array}$ \\
\hline
\end{tabular}

TABLA IV. CARACTERÍSTICAS DE LOS ARTÍCULOS INCLUIDOS SOBRE DOLOR CERVICAL

\begin{tabular}{|c|c|c|c|c|}
\hline Autor/Año & $\begin{array}{l}\text { Condición/Método de } \\
\text { aleatorización }\end{array}$ & $\begin{array}{c}\text { Características de } \\
\text { pacientes }\end{array}$ & Intervención & $\begin{array}{c}\text { Seguimiento/Medidas } \\
\text { de resultado }\end{array}$ \\
\hline $\begin{array}{l}\text { Dziedzic et al. (56) } \\
2005\end{array}$ & $\begin{array}{l}\text { MDA: central } \\
\text { generada por un } \\
\text { computador } \\
\text { Pacientes con dolor } \\
\text { cervical inespecífico } \\
\text { (Dg. clínico) } \\
\text { Grupo 1: } \\
\text { programa de } \\
\text { tratamiento con } \\
\text { asesoramiento y ej. } \\
\text { activos y resistidos de } \\
\text { Col. cervical } \\
\text { Grupo 2: } \\
\text { programa de } \\
\text { tratamiento con } \\
\text { asesoramiento y } \\
\text { ej. similar al grupo } \\
\text { anterior más terapia } \\
\text { manual (TM) } \\
\text { Grupo 3: } \\
\text { programa de } \\
\text { tratamiento con } \\
\text { asesoramiento y } \\
\text { ej. similar al grupo } \\
\text { anterior más OCP }\end{array}$ & $\begin{array}{l}\mathrm{n}=350 \text { pacientes } \\
\text { Edad media: } 51 \text { años } \\
\text { Rango de edad: } 23-84 \\
\text { años } \\
\text { Grupo 1: } \\
\mathrm{n}=115\end{array}$ & $\begin{array}{l}\text { Intervención: } 6 \\
\text { semanas } \\
\text { Grupo 1: } \\
\text { tratamiento de } \\
\text { asesoramiento } \\
\text { con indicaciones } \\
\text { individuales y } \\
\text { ejercicios activos y } \\
\text { resistidos de Col. } \\
\text { cervical (20 min, } 8 \\
\text { sesiones) } \\
\text { Grupo 2: } \\
\text { tratamiento con } \\
\text { asesoramiento y ej. } \\
\text { más TM } \\
\text { Grupo 3: } \\
\text { tratamiento con } \\
\text { asesoramiento y } \\
\text { ej. similar al grupo } \\
\text { anterior y OCP } \\
\text { intensidad de } 7,4 \mathrm{~W} \text {, } \\
\text { durante } 15 \text { minutos }\end{array}$ & $\begin{array}{l}\text { Seguimiento: } 6 \text { meses } \\
\text { Medidas de resultado } \\
\text { Dolor: Northwick } \\
\text { Park Neck Pain } \\
\text { Questionnaire (NPQ) } \\
\text { Evaluación global }\end{array}$ \\
\hline $\begin{array}{l}\text { Lewis et al. (57) } \\
2007\end{array}$ & $\begin{array}{l}M D A \text { : central } \\
\text { generada por un } \\
\text { computador }\end{array}$ & $\begin{array}{l}\mathrm{n}=350 \text { pacientes } \\
\text { Edad media: } 51 \text { años }\end{array}$ & $\begin{array}{l}\text { Intervención: } 6 \\
\text { semanas }\end{array}$ & $\begin{array}{l}\text { Seguimiento: } 6 \text { meses } \\
\text { Medidas de resultado }\end{array}$ \\
\hline
\end{tabular}


TABLA IV (CONT.). CARACTERÍSTICAS DE LOS ARTÍCULOS INCLUIDOS SOBRE DOLOR CERVICAL

\begin{tabular}{|c|c|c|c|c|}
\hline Autor/Año & $\begin{array}{l}\text { Condición/Método de } \\
\text { aleatorización }\end{array}$ & $\begin{array}{c}\text { Características de } \\
\text { pacientes }\end{array}$ & Intervención & $\begin{array}{c}\text { Seguimiento/Medidas } \\
\text { de resultado }\end{array}$ \\
\hline Lewis et al. (57) & $\begin{array}{l}\text { Pacientes con dolor } \\
\text { cervical inespecífico } \\
\text { (Dg. clínico) } \\
\text { Grupo 1: } \\
\text { programa de } \\
\text { tratamiento con } \\
\text { asesoramiento y ej. } \\
\text { activos y resistidos de } \\
\text { Col. cervical } \\
\text { Grupo 2: } \\
\text { programa de } \\
\text { tratamiento con } \\
\text { asesoramiento y } \\
\text { ej. similar al grupo } \\
\text { anterior más terapia } \\
\text { manual (TM) } \\
\text { Grupo 3: } \\
\text { programa de } \\
\text { tratamiento con } \\
\text { asesoramiento y } \\
\text { ej. similar al grupo } \\
\text { anterior más OCP }\end{array}$ & $\begin{array}{l}\text { Grupo 1: } \\
\mathrm{n}=115 \\
\text { Grupo 2: } \\
\mathrm{n}=114 \\
\text { Grupo 3: } \\
\mathrm{n}=121\end{array}$ & $\begin{array}{l}\text { Grupo 1: } \\
\text { tratamiento de } \\
\text { asesoramiento } \\
\text { con indicaciones } \\
\text { individuales y } \\
\text { ejercicios activos y } \\
\text { resistidos de Col. } \\
\text { cervical ( } 20 \text { min, } 8 \\
\text { sesiones) } \\
\text { Grupo 2: } \\
\text { tratamiento con } \\
\text { asesoramiento y ej. } \\
\text { más TM } \\
\text { Grupo 3: } \\
\text { tratamiento con } \\
\text { asesoramiento y } \\
\text { ej. similar al grupo } \\
\text { anterior y OCP } \\
\text { intensidad de } 7,4 \mathrm{~W} \text {, } \\
\text { durante } 15 \text { minutos }\end{array}$ & $\begin{array}{l}\text { Dolor: Northwick } \\
\text { Park Neck Pain } \\
\text { Questionnaire (NPQ) } \\
\text { Estado de salud: EQ- } \\
\text { 5D } \\
\text { Utilidad: QALY } \\
\text { Costos de salud } \\
\text { Costos sociales }\end{array}$ \\
\hline
\end{tabular}

TABLA V. CARACTERÍSTICAS DE LOS ARTÍCULOS INCLUIDOS SOBRE FRACTURA DE CALCÁNEO

\begin{tabular}{|c|c|c|c|c|}
\hline Autor/Año & $\begin{array}{l}\text { Condición/Método de } \\
\text { aleatorización }\end{array}$ & $\begin{array}{c}\text { Características de } \\
\text { pacientes }\end{array}$ & Intervención & $\begin{array}{c}\text { Seguimiento/Medidas } \\
\text { de resultado }\end{array}$ \\
\hline \multirow{5}{*}{$\begin{array}{l}\text { Buzzard et al. (58) } \\
2003\end{array}$} & $\begin{array}{l}M D A \text { : no se reporta } \\
\text { cómo se realizó la } \\
\text { aleatorización }\end{array}$ & $\mathrm{n}=20$ pacientes & Intervención: 5 días & \\
\hline & $\begin{array}{l}\text { Pacientes con fractura } \\
\text { aguda de calcáneo } \\
\text { uni o bilateral }\end{array}$ & $\begin{array}{l}\text { Grupo terapia fría: } \\
\mathrm{n}=11 \\
\text { Edad media: } 44 \text { años } \\
\text { Rango de edad: } 24-67 \\
\text { años }\end{array}$ & $\begin{array}{l}\text { Grupo terapia fría: } \\
\text { tratamiento Cryocuff, } \\
\text { por } 20 \text { min, } 6 \text { veces/ } \\
\text { día, durante } 5 \text { días }\end{array}$ & $\begin{array}{l}\text { Seguimiento: no } \\
\text { tiene, se midió } \\
\text { finalizado el tto. }\end{array}$ \\
\hline & $\begin{array}{l}\text { Grupo de } \\
\text { intervención }\end{array}$ & (DS 15) & $\begin{array}{l}\text { Grupo OCP: } \\
\text { tratamiento con OCP, }\end{array}$ & Medidas de resultado \\
\hline & $\begin{array}{l}\text { con terapia fría } \\
\text { (Cryocuff) }\end{array}$ & $\begin{array}{l}\text { Grupo OCP: } \\
\mathrm{n}=9\end{array}$ & $\begin{array}{l}\text { duración de pulso } \\
200 \mathrm{~ms} \text {, frec. de pulso }\end{array}$ & ROM: goniómetro \\
\hline & $\begin{array}{l}\text { Grupo de } \\
\text { intervención con } \\
\text { OCP }\end{array}$ & $\begin{array}{l}\text { Edad media: } 37 \text { años } \\
\text { Rango de edad: } 19-76 \\
\text { años } \\
\text { (DS 18) }\end{array}$ & $\begin{array}{l}26 \mathrm{~Hz} \text {, intensidad de } \\
35 \mathrm{~W} \text {, sesiones de } \\
15 \mathrm{~min}, 2 \text { veces/día } \\
\text { durante } 5 \text { días }\end{array}$ & $\begin{array}{l}\text { Inflamación: cinta } \\
\text { métrica }\end{array}$ \\
\hline
\end{tabular}


TABLA VI. CARACTERÍSTICAS DE LOS ARTÍCULOS INCLUIDOS SOBRE DOLOR LUMBAR

\begin{tabular}{|c|c|c|c|c|}
\hline Autor/Año & $\begin{array}{c}\text { Condición/Método de } \\
\text { aleatorización }\end{array}$ & $\begin{array}{c}\text { Características de } \\
\text { pacientes }\end{array}$ & Intervención & $\begin{array}{c}\text { Seguimiento/Medición } \\
\text { de resultados }\end{array}$ \\
\hline \multirow{4}{*}{ Ahmed et al. (59) } & $\begin{array}{l}\text { MDA: no se reporta } \\
\text { cómo se realizó la } \\
\text { aleatorización }\end{array}$ & & $\begin{array}{l}\text { Intervención: } 6 \\
\text { semanas }\end{array}$ & \\
\hline & $\begin{array}{l}\text { Pacientes con dolor } \\
\text { lumbar crónico }>3 \\
\text { meses }\end{array}$ & $\begin{array}{l}\text { Edad: } 30-49 \text { años } \\
\text { Edad media: } 39,72 \\
\text { años (DS } 11,94)\end{array}$ & $\begin{array}{l}\text { Grupo A: } \\
\text { AINEs (meloxicam } \\
15 \mathrm{mg} \text { ) } 1 \text { vez/día, ej. } \\
\text { y OCC, } 15 \mathrm{~min}, 3 \\
\text { veces/semana }\end{array}$ & $\begin{array}{l}\text { Seguimiento: no } \\
\text { tiene, se midió } \\
\text { finalizado el tto. } \\
\text { Medidas de resultado }\end{array}$ \\
\hline & $\begin{array}{l}\text { de tratamiento con } \\
\text { OCC, AINEs y } \\
\text { ejercicios }\end{array}$ & $\begin{array}{l}\text { Grupo A: } \\
\mathrm{n}=47\end{array}$ & \multirow{2}{*}{$\begin{array}{l}\text { Grupo B: } \\
\text { AINES y ej. (similar } \\
\text { al grupo anterior) } \\
\text { más OCC placebo } \\
\text { (máquina apagada), } \\
15 \text { min, } 3 \text { veces/ } \\
\text { semana }\end{array}$} & $\begin{array}{l}\text { Dolor: Lattinen Test } \\
\text { Score y EVA }\end{array}$ \\
\hline & $\begin{array}{l}\text { Grupo B: programa } \\
\text { de tratamiento con } \\
\text { OCC (máquina } \\
\text { apagada), AINEs y } \\
\text { ejercicios }\end{array}$ & $\begin{array}{l}\text { Grupo B: } \\
\mathrm{n}=50\end{array}$ & & Score de rigidez \\
\hline
\end{tabular}

Bindal et al. (60)

2007

Kumar et al. (61)

2009
$M D A$ : no se reporta cómo se realizó la aleatorización

Pacientes estudiantes género masculino con Rango de edad: 17dolor lumbar

24 años

Grupo I: programa de Grupo 1: tratamiento con OCP $\mathrm{n}=15$ y ejercicios

Grupo II: programa de tratamiento con calentamiento y yoga

\section{Grupo 2:} $\mathrm{n}=15$
Intervención: 3

semanas

$\mathrm{n}=30$ pacientes $\quad$ Grupo I:

hombres OCP por $10 \mathrm{~min}$ y ej.

(flexión, retroversión, Seguimiento: 6 rodillas al pecho y semanas

extensión) por 15

sesiones, 5 veces/

semana

Grupo II:

tratamiento con calentamiento 10 min y yoga asanas, 15 sesiones, 5 veces/ semana
Medidas de resultado

Dolor: escala ordinal de 5 puntos
$M D A$ : se realizó al azar con lotería

Pacientes jóvenes deportistas con dolor lumbar inespecífico subagudo o crónico

Grupo 1: programa de tratamiento convencional; US + OCC y ejercicios de fortalecimiento

$$
\mathrm{n}=30 \text { pacientes }
$$

Rango de edad: 18 a 28 años

\section{Grupo 1:}

$\mathrm{n}=15$

Edad media: 23,40

años

(DS 3,27)
Intervención: durante 35 días (5 semanas)

Grupo 1:

US frec. $1 \mathrm{MHz}$, intensidad 1,2 W/ $\mathrm{cm} 2,8 \mathrm{~min}, \mathrm{OCC}$ por $15 \mathrm{~min}$ y ej. de fortalecimiento con 10 repeticiones por 18 sesiones
Seguimiento: no tiene, se midió finalizado el tto.

Medidas de resultado

Dolor: EVA

Pruebas funcionales. (caminar 5 minutos, levantarse de una silla, subir y bajar escaleras) 
TABLA VI (CONT.). CARACTERÍSTICAS DE LOS ARTÍCULOS INCLUIDOS SOBRE DOLOR LUMBAR

\begin{tabular}{|c|c|c|c|c|}
\hline Autor/Año & $\begin{array}{l}\text { Condición/Método de } \\
\text { aleatorización }\end{array}$ & $\begin{array}{c}\text { Características de } \\
\text { pacientes }\end{array}$ & Intervención & $\begin{array}{c}\text { Seguimiento/Medición } \\
\text { de resultados }\end{array}$ \\
\hline $\begin{array}{l}\text { Kumar et al. (61) } \\
2009\end{array}$ & $\begin{array}{l}\text { Grupo 2: programa } \\
\text { de tratamiento con } \\
\text { técnica dinámica } \\
\text { de estabilización } \\
\text { muscular (DMST) }\end{array}$ & $\begin{array}{l}\text { Grupo 2: } \\
\mathrm{n}=15 \\
\text { Edad media: } 24,07 \\
\text { años } \\
\text { (DS 2,89) }\end{array}$ & $\begin{array}{l}\text { Grupo 2: } \\
\text { tratamiento con } \\
\text { técnica dinámica } \\
\text { de estabilización } \\
\text { muscular (TDEM) } \\
\text { durante } 5 \text { semanas }\end{array}$ & \\
\hline \multirow{6}{*}{ Shakoor et al. (62) } & $\begin{array}{l}M D A: \text { se realizó al } \\
\text { azar con lotería }\end{array}$ & $\mathrm{n}=102$ pacientes & $\begin{array}{l}\text { Intervención: } 6 \\
\text { semanas }\end{array}$ & \\
\hline & $\begin{array}{l}\text { Pacientes con dolor } \\
\text { lumbar crónico }>3\end{array}$ & $\begin{array}{l}42 \text { hombres y } 60 \\
\text { mujeres }\end{array}$ & \multirow{4}{*}{$\begin{array}{l}\text { Grupo A: } \\
\text { OCC por } 15 \text { min, } 3 \\
\text { veces/semana, AINEs } \\
\text { (naproxeno } 250 \mathrm{mg} \text { ) } \\
2 \text { veces/día y ej. } \\
\text { de fortalecimiento } \\
\text { en extensión, } 10 \\
\text { repeticiones, } 2 \text { veces/ } \\
\text { día }\end{array}$} & \multirow[b]{2}{*}{$\begin{array}{l}\text { Seguimiento: no } \\
\text { tiene, se midió } \\
\text { finalizado el tto. }\end{array}$} \\
\hline & $\begin{array}{l}\text { Grupo } A \text { : programa } \\
\text { de tratamiento }\end{array}$ & $\begin{array}{l}\text { Edad media: } 42,22+ \\
8,07 \text { años } \\
\text { (DS } 8,07)\end{array}$ & & \\
\hline & $\begin{array}{l}\text { con OCC, AINEs } \\
\text { y ejercicios de } \\
\text { fortalecimiento }\end{array}$ & $\begin{array}{l}\text { Grupo } A \text { : } \\
\mathrm{n}=50\end{array}$ & & Medidas de resultado \\
\hline & & $\begin{array}{l}\text { Edad: } 44,50 \text { años } \\
\text { (DS 8.94) }\end{array}$ & & \multirow{2}{*}{$\begin{array}{l}\text { Dolor: EVA y } \\
\text { Lattinen Test Score }\end{array}$} \\
\hline & $\begin{array}{l}\text { Grupo B: programa } \\
\text { de tratamiento } \\
\text { con OCC placebo } \\
\text { (máquina apagada), } \\
\text { AINEs y ejercicios de } \\
\text { fortalecimiento }\end{array}$ & $\begin{array}{l}\text { Grupo B: } \\
\mathrm{n}=52 \\
\text { Edad: } 40,02 \text { años } \\
\text { (DS 6,49) }\end{array}$ & $\begin{array}{l}\text { Grupo B: } \\
\text { OCC placebo, } 15 \\
\text { min, } 3 \text { veces/semana, } \\
\text { AINEs y ej. similar al } \\
\text { grupo anterior }\end{array}$ & \\
\hline
\end{tabular}

TABLA VII. CARACTERÍSTICAS DE LOS ARTÍCULOS INCLUIDOS CON PATOLOGÍAS DE HOMBRO

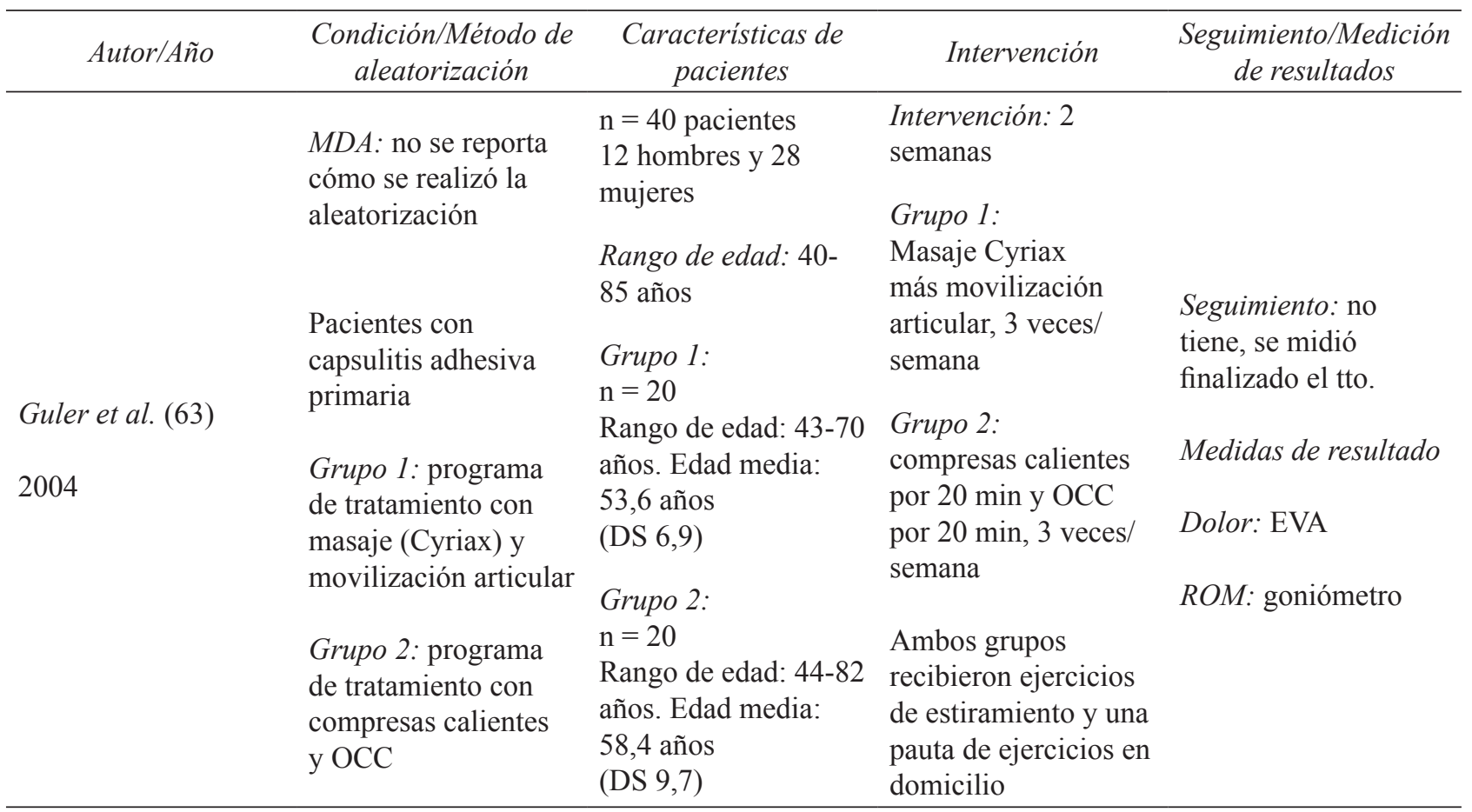


TABLA VII (CONT.). CARACTERÍSTICAS DE LOS ARTÍCULOS INCLUIDOS CON PATOLOGÍAS DE HOMBRO

\begin{tabular}{|c|c|c|c|c|}
\hline Autor/Año & $\begin{array}{l}\text { Condición/Método de } \\
\text { aleatorización }\end{array}$ & $\begin{array}{c}\text { Características de } \\
\text { pacientes }\end{array}$ & Intervención & $\begin{array}{c}\text { Seguimiento/Medición } \\
\text { de resultados }\end{array}$ \\
\hline Jiménez et al. (64) & $\begin{array}{l}\text { MDA: No se reporta } \\
\text { cómo se realizó la } \\
\text { aleatorización } \\
\text { Pacientes con } \\
\text { tendinopatía cálcica } \\
\text { de hombro } \\
\text { (Dg clínico y Rx) } \\
\text { Grupo 1: programa } \\
\text { de tratamiento con } \\
\text { US, OCC y pauta de } \\
\text { ej. en domicilio }\end{array}$ & $\begin{array}{l}\mathrm{n}=23 \text { pacientes } \\
\text { Grupo } 1 \text { : } \\
\mathrm{n}=12 ; 2 \text { hombres y } \\
10 \text { mujeres } \\
\text { Rango de edad: } \\
42-75 \text { años } \\
\text { Edad media } 54,33 \\
\text { años } \\
\text { Grupo } 2 \text { : } \\
\mathrm{n}=11 ; 10 \text { mujeres y } \\
1 \text { hombre } \\
\text { Rango de edad: } \\
41-62 \text { años } \\
\text { Edad media } 54,9 \\
\text { años }\end{array}$ & $\begin{array}{l}\text { Intervención: } 3 \\
\text { semanas } \\
\text { Grupo 1: } \\
\text { US frec. } 1 \mathrm{MHz}, \\
\text { intensidad de } 1 \mathrm{~W} / \\
\mathrm{cm}^{2}, 5 \text { min y OCC, } \\
\text { potencia salida } 24 \mathrm{~W} \text {, } \\
5 \text { veces/semana } \\
\text { Grupo } 2 \text { : } \\
\text { US, similar al grupo } \\
\text { anterior y IAA } \\
\text { intensidad } 3 \mathrm{~mA} \\
\text { durante } 15 \text { min } 5 \\
\text { veces/semana } \\
\text { Ambos grupos } \\
\text { recibieron ej. en } \\
\text { domiciliario (flexión, } \\
\text { abducción y rotación } \\
\text { de hombro) } 10 \\
\text { repeticiones, } 2 \text { veces } \\
\text { /día }\end{array}$ & $\begin{array}{l}\text { Seguimiento: no } \\
\text { tiene, se midió } \\
\text { finalizado el tto. } \\
\text { Medidas de resultado }\end{array}$ \\
\hline
\end{tabular}

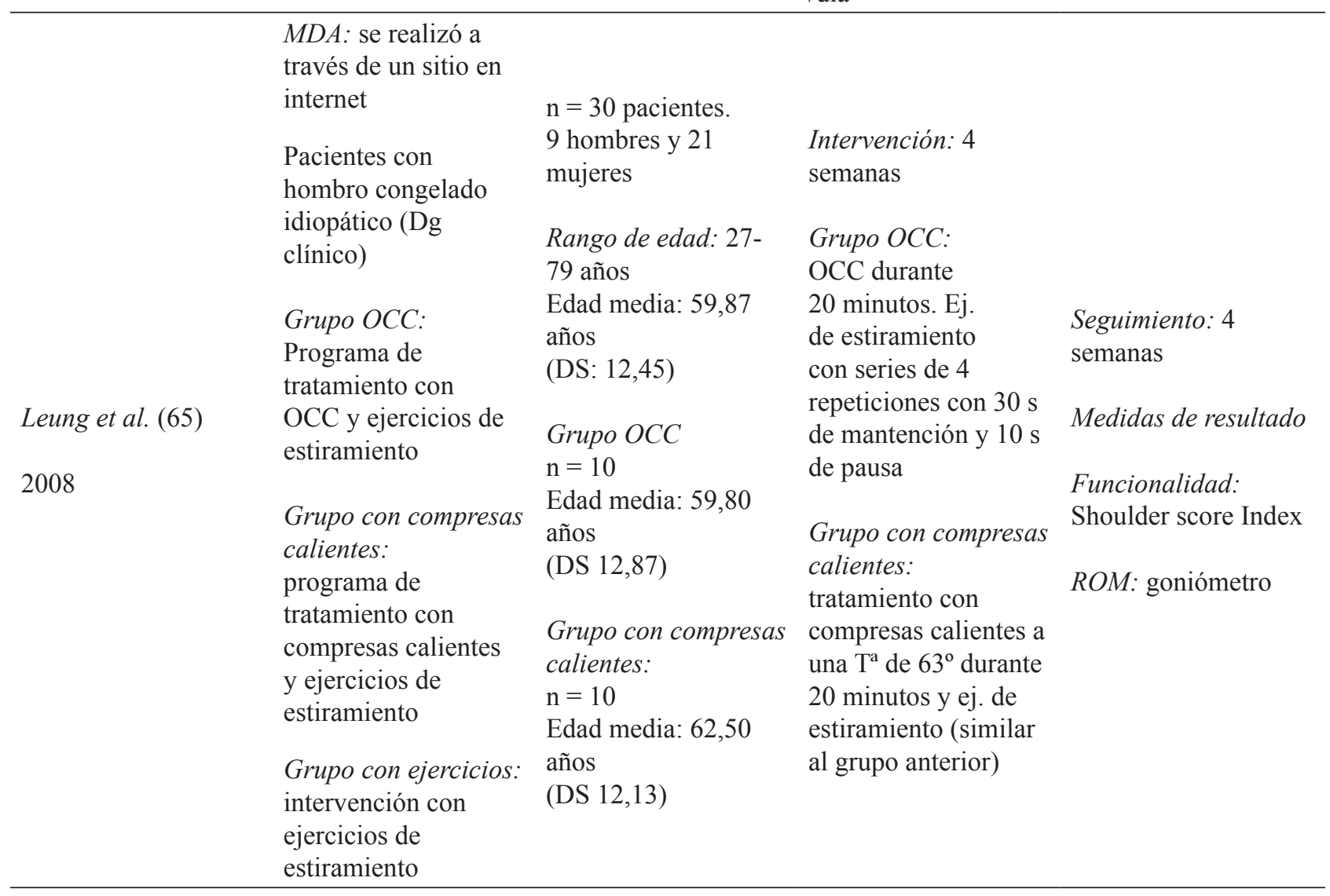


TABLA VII (CONT.). CARACTERÍSTICAS DE LOS ARTÍCULOS INCLUIDOS CON PATOLOGÍAS DE HOMBRO

\begin{tabular}{|c|c|c|c|c|}
\hline Autor/Año & $\begin{array}{l}\text { Condición/Método de } \\
\text { aleatorización }\end{array}$ & $\begin{array}{l}\text { Características de } \\
\text { pacientes }\end{array}$ & Intervención & $\begin{array}{c}\text { Seguimiento/Medición } \\
\text { de resultados }\end{array}$ \\
\hline Leung et al. (65) & & $\begin{array}{l}\text { Grupo con ejercicios: } \\
\mathrm{n}=10 \\
\text { Edad media: }\end{array}$ & $\begin{array}{l}\text { Grupo con ejercicios: } \\
\text { tratamiento con ej. de } \\
\text { estiramiento (similar } \\
\text { al grupo anterior) }\end{array}$ & \\
\hline 2008 & & $\begin{array}{l}57,30 \text { años } \\
\text { (DS } 13,10)\end{array}$ & $\begin{array}{l}\text { Para los } 3 \text { grupos el } \\
\text { tratamiento fue de } \\
12 \text { sesiones, } 3 \text { veces/ } \\
\text { semana }\end{array}$ & \\
\hline
\end{tabular}

MDA: Método de aleatorización. OCC: Onda corta continua. OCP: Onda corta pulsada. OA: Osteoartritis de rodilla. TENS: Estimulación nerviosa eléctrica transcutánea. IR: Infrarrojo. TIF: Terapia interferencial. AVD: Actividades de la vida diaria. CI: Corriente interferencial. AINEs: Antiinflamatorios no esteroidales. EEII: Extremidades inferiores. DS: Desviación estándar. Ej: Ejercicios.US: Ultrasonido.

\section{OC sola versus un programa de tratamiento}

Tres estudios $(43,45,49)$, con un $n=154$ pacientes, investigaron la efectividad de la OC sola comparado con un programa de tratamiento, en pacientes con osteoartritis de rodilla.

Bezalel et al. (43), con un $\mathrm{n}=50$ pacientes, comparó la efectividad de la OCC versus un programa educacional y una pauta de ejercicios en domicilio. La OCC se ocupó como grupo control, no hubo cálculo de dosis, se realizaron 6 sesiones de 20 minutos, la duración total del tratamiento fue de 4 semanas, las medidas de resultado estudiadas fueron funcionalidad (WOMAC y pruebas de pararse, sentarse y caminar), el estudio contempló un seguimiento de 4 semanas; al finalizar el tratamiento, ambos grupos mejoraron casi todas las variables estudiadas, salvo la subescala de WOMAC de rigidez, comparado con los datos basales, el WOMAC total disminuyó 9,5 puntos (IC $95 \%-12,3$ a $-6,7$ ) y el tiempo promedio de levantarse y caminar disminuyó $1,5 \mathrm{~s}$ (IC $-2,3$ a - $-0,7$ s). Sin embargo, no hubo diferencia significativa entre los grupos. Al finalizar el seguimiento, solo el grupo con programa educacional más ejercicios continúa mejorando las mediciones, el WOMAC total disminuyó 9 puntos (IC $-14,5$ a $-3,4)$ y el tiempo promedio de levantarse y caminar disminuyó 2,1 s (IC -3,7 a -0,6). Pese a que el estudio no especifica cómo fue realizado el análisis estadístico entre los grupos, los autores concluyen que el grupo de programa educacional más ejercicios muestra una mejoría continua de las variables estudiadas en comparación con el control.

Cantarini et al. (45), con un $\mathrm{n}=74$ pacientes, comparó la efectividad de la OCC versus un programa de tratamiento con Spa y un control con cuidados ambulatorios de rutina. Para la OCC no hubo cálculo de dosis, se realizaron 10 sesiones de 15 minutos cada una, 3 veces por semana, la duración total del tratamiento fue de 3 semanas, las medidas de resultado estudiadas fueron: dolor (EVA y consumo de analgésicos), funcionalidad (ALQ), calidad de vida (AIMS). El estudio contempló un seguimiento de 12 semanas, en donde se realizó un análisis multivarianza (Manova), que muestra una reducción significativa del dolor espontáneo al finalizar las 3 semanas $(p<0,01)$ a favor del grupo Spa y OCC versus el control; sin embargo, a las 12 semanas solo el grupo Spa mantiene la reducción del dolor comparado con los otros 2 grupos ( $<<0,01)$; para el ALQ, AIMS y consumo de analgésicos ocurre lo mismo, solo el grupo Spa mantiene los efectos al finalizar el seguimiento comparado con los otros 2 grupos.

Jan et al. (49), con un $\mathrm{n}=30$ pacientes, comparó la efectividad de la OCC versus un grupo con OCC más AINEs y un grupo control sin intervención. Para la OCC no hubo cálculo de dosis, se realizaron 30 sesiones de 20 minutos cada una, 3 a 5 veces por semana, la duración total del tratamiento fue de 8 semanas, las medidas de resultado estudiadas fueron: dolor (EVA) e inflamación (ultrasonografía). El estudio contempló un seguimiento de 3 semanas, en donde se realizó un análisis multivarianza (Anova), que muestra una reducción del dolor en los 3 grupos comparado con los datos basales; sin embargo, al comparar entre los grupos, existe una diferencia estadísticamente significativa a favor de los 2 grupos de tratamiento comparados con el control $(\mathrm{p}<0,005)$. Al comparar la reducción del dolor entre ambos grupos, la diferencia no fue significativa ( $p>$ $0,05)$, la inflamación también tiene resultados similares al dolor, hubo una reducción significativa en ambos grupos de tratamiento, comparados con el control desde la sesión $10(\mathrm{p}<0,0005)$, que se acentúa mas en la sesión $30(\mathrm{p}<$ $0,0001)$. 


\section{Programa de tratamiento que incluya $O C$ versus otra intervención sola}

Dos estudios $(40,61)$, con un $n=70$ pacientes, investigaron la efectividad de un programa de tratamiento que incluía OC versus otra intervención sola, en pacientes con $\mathrm{OA}$ de rodilla y SD lumbar inespecífico.

Akyol et al. (40), con un $\mathrm{n}=40$ pacientes, comparó la efectividad de un programa de tratamiento con OCC más ejercicio isocinético versus un grupo con ejercicio isocinético solo en pacientes con OA de rodilla. Para la OCC no hubo cálculo de dosis, se realizaron 12 sesiones de 20 minutos cada una, 3 veces por semana, la duración total del tratamiento fue de 4 semanas, las medidas de resultado estudiadas fueron: dolor (EVA), funcionalidad (WOMAC y distancia de caminar), calidad de vida (SF-36), depresión (BDI) y fuerza muscular con dinamómetro. El estudio contempló un seguimiento de 3 meses, en donde ambos grupos muestran una mejoría en todas las variables estudiadas comparado con los datos basales, pero al comparar entre los grupos no hubo diferencia estadísticamente significativa: EVA $(p=0,58)$, WOMAC subescala de dolor $(p=0,70)$, subescala de rigidez $(\mathrm{p}=0,3)$, subescala de función $(\mathrm{p}=$ $0,70)$, distancia de marcha 6 minutos $(\mathrm{p}=0,06)$, BDI $(\mathrm{p}=$ $0,94)$ y SF-36 $(\mathrm{p}>0,05)$.

Kumar et al. (61), con un $\mathrm{n}=30$ pacientes, comparó la efectividad de un programa de tratamiento con US, OCC y ejercicios de fortalecimiento versus un grupo con técnicas de estabilización dinámica muscular en pacientes jóvenes con SD lumbar inespecífico subagudo y crónico. Para la OCC no hubo cálculo de dosis, se realizaron 18 sesiones de 15 minutos, la duración del tratamiento total fue de 5 semanas, las medidas de resultado estudiadas fueron: dolor (EVA), funcionalidad (tiempo de caminar 5 minutos, levantarse de una silla, subir y bajar escaleras). El estudio no contempló seguimiento. En donde ambos grupos muestran una mejoría en todas las variables estudiadas comparado con los datos basales, pero al comparar entre los grupos no hubo diferencia estadísticamente significativa en la EVA ( $p>0,05)$, pero sí en caminar 5 minutos, levantarse de una silla, subir y bajar escaleras $(\mathrm{p}<$ 0,01) a favor del grupo de ejercicios de estabilización.

\section{Programa de tratamiento que incluya $O C$ versus otro programa de tratamiento}

Catorce estudios $(41,42,46,52-54,56,57,59,60,62-65)$, con un $\mathrm{n}=1.710$ pacientes, investigaron la efectividad de un programa de tratamiento que incluía OC versus otro programa de tratamiento, en pacientes con OA de rodilla, dolor cervical, SD lumbar, capsulitis adhesiva y tendinitis cálcica de hombro.

Seis estudios $(41,42,46,52-54)$ con un $n=688$ en pacientes con OA de rodilla:
Atamaz et al. (41), con un $\mathrm{n}=85$ pacientes, comparó la efectividad de un programa de tratamiento con agentes físicos (OCP, infrarrojo y terapia interferencial) versus un grupo con 2 tipos de inyecciones intraarticulares. Para la OCP no hubo cálculo de dosis, se realizaron 15 sesiones, 5 veces por semana, la duración total del tratamiento fue de 3 semanas, las medidas de resultado estudiadas fueron: dolor (EVA), goniometría, funcionalidad (WOMAC, SF-36, tiempo de caminar $15 \mathrm{~m}$ ). El estudio contempló un seguimiento a 1, 3, 6, 9 y 12 meses, en donde se realizó un análisis multivarianza (Anova). Ambos grupos muestran una mejoría en la mayoría de las variables estudiadas al finalizar el estudio comparado con los datos basales, aunque la disminución del dolor (nocturno, al tocar, en reposo e ítem del SF-36) y el ítem de función del SF-36 fue mayor en el grupo de agentes físicos al $1^{\circ}, 3^{\circ}$ y $6^{\circ}$ mes $(p<0,05)$.

Atamaz et al. (42), con un $\mathrm{n}=203$ pacientes, comparó la efectividad de varios agentes físicos en un programa de tratamiento al que se adicionaba ejercicios y educación. Grupo $n^{\circ} 1$ : Tens placebo, grupo $n^{\circ} 2$ : Tens, grupo $n^{\circ} 3$ : corriente interferencial placebo, grupo $n^{\circ} 4$ : corriente interferencial, grupo $\mathrm{n}^{\circ}$ 5: OCC placebo y grupo $\mathrm{n}^{\circ}$ 6: OCC. Para la OCC no hubo cálculo de dosis, se realizaron 15 sesiones, 5 veces a la semana, la duración total del tratamiento fue de 3 semanas, las medidas de resultado estudiadas fueron: dolor (EVA, consumo de analgésicos), funcionalidad (tiempo de caminar, WOMAC, NHP) y goniometría. El estudio contempló un seguimiento de 6 meses, en donde todos los grupos presentan una mejoría de la mayoría de los parámetros estudiados comparado con los datos basales $(\mathrm{p}<0,05)$, pero sin una diferencia significativa entre los grupos. Al comparar los grupos activos con su correspondiente grupo placebo, solo la ingesta de paracetamol al tercer mes fue significativamente menor en los grupos activos $(p<0,05)$ y los pacientes tratados con corriente interferencial también al $6^{\circ}$ mes $(\mathrm{p}=0,003)$.

Cetin et al. (46), con un $\mathrm{n}=100$ pacientes, comparó la efectividad de varios agentes físicos adicionado a un programa de ejercicio isocinético. Grupo $\mathrm{n}^{\circ} 1$ : OCC más $\mathrm{CHC}$, grupo $\mathrm{n}^{\circ} 2$ : Tens más $\mathrm{CHC}$, grupo $\mathrm{n}^{\circ} 3$ : US más $\mathrm{CHC}$, grupo $\mathrm{n}^{\circ} 4 \mathrm{CHC}$ y grupo $\mathrm{n}^{\circ} 5$ : solo ejercicios isocinéticos. Para la OCC no hubo cálculo de dosis, se realizaron 24 sesiones de 15 minutos cada una, 3 veces por semana, la duración total del tratamiento fue de 8 semanas, las medidas de resultado estudiadas fueron: dolor (EVA), funcionalidad (ALQ y tiempo de caminar), discapacidad y fuerza con dinamómetro. El estudio no contempló seguimiento. En donde se realizó el análisis estadístico con Kruskal-Wallis ya que los datos no distribuían en forma normal, todos los grupos presentan una mejoría significativa en el dolor, tiempo de caminar, discapacidad y fuerza de torque comparado con los datos basales $(\mathrm{p}=0,0001)$. Al realizar la compararación entre los grupos, los datos de la EVA y ALQ fueron significativamente menor en los grupos de agentes 
físicos comparados con el grupo 5 control $(\mathrm{p}=0,019 \mathrm{y} \mathrm{p}=$ 0,018 respectivamente), la fuerza muscular en las diferentes velocidades angulares fue significativamente mayor en los grupos 1, 2 y 3 comparados con el control $(\mathrm{p}<0,05)$.

Rattanachaiyanont et al. (52), con un $n=113$ pacientes, comparó la efectividad de adicionar OCC a un programa de ejercicios versus OCC apagada (placebo) más ejercicios. Para la OCC no hubo cálculo de dosis, se realizaron 9 sesiones de 20 minutos cada una, 3 veces por semana, la duración total del tratamiento fue de 3 semanas, las medidas de resultado estudiadas fueron: funcionalidad (WOMAC, velocidad de caminar $100 \mathrm{~m}$, subir y bajar escaleras), evaluación global, índice de satisfacción y consumo de analgésicos. El estudio contempló un seguimiento de 3 semanas. Todos los pacientes muestran una mejoría en todos los parámetros estudiados comparado con los datos basales; sin embargo, al realizar la comparación entre los grupos, no hubo diferencia estadísticamente significativa $(\mathrm{p}>0,05)$ para ninguna de las variables estudiadas.

Shakoor et al. (53), con un $\mathrm{n}=162$ pacientes, comparó la efectividad de un programa de tratamiento con OCC, ejercicios, AINEs y modificación de las actividades (grupo A) versus un grupo B con OCC, ejercicios y AINEs. Para la OCC no hubo cálculo de dosis, la duración total del tratamiento fue de 6 semanas, las medidas de resultado estudiadas fueron: dolor (EVA, LTS) y goniómetro. El estudio no contempló seguimiento. Ambos grupos muestran una mejoría gradual y significativa de las variables observadas comparado con los datos basales; sin embargo, al realizar la comparación entre los grupos, para el score total de dolor solo hubo una reducción significativa a favor del grupo A en la $6^{\mathrm{a}}$ semana (IC $95 \%-3,45$ a $-0,70$ ).

Silva et al. (54), con un $\mathrm{n}=25$ pacientes, comparo la efectividad de un programa de tratamiento con OCC más ejercicios (grupo A) versus crioterapia más ejercicios (grupo B) y un control solo con ejercicios (grupo C). Para la OCC no hubo cálculo de dosis, se realizaron 10 sesiones de 20 minutos cada una, 2 veces por semana, la duración total del tratamiento fue de 5 semanas, las medidas de resultado estudiadas fueron: dolor (Borg), funcionalidad (ALQ), goniometría y fuerza muscular. El estudio no contempló seguimiento. Para el dolor solo hubo una disminución significativa en el grupo B ( $p=0,03125)$, la funcionalidad y flexibilidad mejoró en los 3 grupos, la mejoría del rango de movimiento fue similar para el grupo $\mathrm{B}$ y $\mathrm{C}$, la fuerza muscular de los flexores solo mejoró en el grupo $\mathrm{C}$ y para los extensores solo mejoró en los grupos $\mathrm{B}$ y $\mathrm{C}$, solo se reportó pérdida de fuerza en el grupo A.

Evaluamos la homogeneidad clínica de los grupos $\mathrm{n}^{\circ}$ 5 y 6 del estudio de Atamaz et al. (42) con los grupos del estudio de Rattanachaiyanont et al. (52). Sin embargo, el número de sesiones de $\mathrm{OC}$ y la periodicidad del tratamiento fue diferente en ambos estudios, el programa de ejercicios también fue diferente y la educacion solo fue brindada en el estudio de Atamaz et al. (42), por lo tanto, no fue posible comparar estos estudios en base a un estimador puntual.

Dos estudios $(56,57)$ con un $\mathrm{n}=700$ en pacientes con dolor cervical inespecífico:

Dziedzic et al. (56), con un $\mathrm{n}=350$ pacientes, comparó la efectividad de un programa de tratamiento con ejercicios más asesoramiento (grupo $\mathrm{n}^{\circ} 1$ ) versus ejercicios, asesoramiento más terapia manual (grupo $\mathrm{n}^{\circ} 2$ ) y ejercicios, asesoramiento más OCP (grupo $n^{\circ} 3$ ). Para la OCP no hubo cálculo de dosis, se realizaron sesiones de 15 minutos, la duración total del tratamiento fue de 6 semanas, las medidas de resultado estudiadas fueron: dolor (NPQ) y evaluación global. El estudio contempló un seguimiento de 6 meses, los tres grupos muestran una mejoría gradual y significativa de las variables observadas comparado con los datos basales; sin embargo, al realizar la comparación entre los grupos, no hubo diferencia significativa en ninguna de las variables estudiadas.

Lewis et al. (57), con un $\mathrm{n}=350$ pacientes, realizó un análisis comparativo de costo- efectividad y costo-utilidad entre un programa de tratamiento con ejercicios más asesoramiento (grupo $\mathrm{n}^{\circ} 1$ ) versus ejercicios, asesoramiento más terapia manual (grupo $\mathrm{n}^{\circ} 2$ ) y ejercicios, asesoramiento más OCP (grupo $\mathrm{n}^{\circ} 3$ ). Para la OCP no hubo cálculo de dosis, se realizaron sesiones de 15 minutos, la duración total del tratamiento fue de 6 semanas, las medidas de resultado estudiadas fueron: dolor (NPQ), utilidad (QALY), estado de salud (EQ-5D) y se calcularon costos de salud y sociales (costos asociados a la pérdida de productividad). El estudio contempló un seguimiento de 6 meses. El estudio muestra que los grupos con ejercicios más asesoramiento y ejercicios, asesoramiento más terapia manual, son más costo-efectivos que el grupo con OCP en pacientes con dolor cervical inespecífico.

Si bien es cierto que estos dos artículos se publican en revistas diferentes, es el mismo grupo de investigadores y los pacientes son los mismos para ambos estudios, por lo tanto, tampoco es plausible poder juntarlos en un estimador puntual.

Tres estudios $(59,60,62)$ con un $n=229$ en pacientes con síndrome de dolor lumbar (SDL):

Ahmed et al. (59), con un $\mathrm{n}=97$ pacientes, comparó la efectividad de un programa de tratamiento con OCC, AINEs y ejercicios (grupo A) versus un grupo con OC apagada, AINEs y ejercicios (grupo B) en pacientes con SDL crónico ( $>3$ meses). Para la OCC no hubo cálculo de dosis, se realizaron 18 sesiones de 15 minutos cada una, 3 veces por semana, con una duración total del tratamiento de 6 semanas, las medidas de resultado estudiadas fueron: dolor (LTS y EVA) y un score de rigidez. El estudio no contempló seguimiento. Ambos grupos muestran una mejoría de las variables observadas comparado con los datos basales; sin embargo, al realizar la comparación entre los grupos, existe una diferencia estadísticamente significativa a favor 
del grupo A, desde la $3^{\mathrm{a}}$ semana (IC $95 \%-4,43$ a $-0,83$ $\mathrm{p}=0,005)$ que se ve incrementado hasta la $6^{\mathrm{a}}$ semana de tratamiento (IC $95 \%-8,17$ a $-5,68 \mathrm{p}=0,0)$.

Bindal et al. (60), con un $\mathrm{n}=30$ pacientes, comparó la efectividad de un programa de yoga versus un grupo de fisioterapia (OCP más ejercicios) en estudiantes con SDL. Para la OCP no hubo cálculo de dosis, se realizaron 15 sesiones de 10 minutos cada una, 5 veces a la semana, la duración total del tratamiento fue de 3 semanas, la medida de resultado estudiada fue: dolor (escala ordinal de 5 puntos). El estudio contempló un seguimiento de 6 semanas. Ambos grupos muestran una mejoría significativa de la variable observada comparado con los datos basales, pero al realizar la comparación entre los grupos, no existe diferencia significativa entre ambos $(\mathrm{p}=0,957)$.

Shakoor et al. (62), con un $\mathrm{n}=102$ pacientes, comparó la efectividad de un programa de tratamiento con OCC, AINEs y ejercicios de fortalecimiento (grupo A) versus un grupo con OC apagada, AINEs y ejercicios de fortalecimiento (grupo B) en pacientes con SDL crónico (> 3 meses). Para la OCC no hubo cálculo de dosis, se realizaron 18 sesiones de 15 minutos cada una, 3 veces por semana, con una duración total del tratamiento de 6 semanas, las medidas de resultado estudiadas fueron: dolor (EVA y LTS). El estudio no contempló seguimiento. Ambos grupos muestran una mejoría significativa de las variables observadas comparado con los datos basales; sin embargo, al realizar la comparación entre los grupos, existe una diferencia estadísticamente significativa a favor del grupo A, desde la $3^{\mathrm{a}}$ semana (IC $95 \%-2,27$ a $-0,02 \mathrm{p}=0,05)$ que se ve incrementada hasta la $6^{\mathrm{a}}$ semana de tratamiento (IC $95 \%-3,75 \mathrm{a}-1,12 \mathrm{p}=0,00$ ).

Evaluamos la homogeneidad clínica del estudio de Ahmed et al. (59) y el de Shakoor et al. (62), sin bien es cierto que la dosis de OCC en ambos estudios es similar (15 minutos, 3 veces por semana, durante 6 semanas), sin embargo, el primero usó meloxicam oral $15 \mathrm{mg} 1 \mathrm{vez}$ al día, más un programa de ejercicios realizado en domicilio (que no se detalla) e instrucciones para la vida diaria, reportó los datos de los pacientes en un valor total que se obtuvo adicionando el LTS, EVA y score de rigidez (0-34 puntos). Por el contrario, el segundo estudio usó naproxeno oral de $250 \mathrm{mg} 2$ veces al día, más un programa de ejercicios de fortalecimiento en extensión de 10 repeticiones, 2 veces al día por 6 semanas e instrucciones para la vida diaria y reportó los datos en un score que se obtuvo adicionando solo el LTS y la EVA (0-30 puntos). Por lo tanto, consideramos que no es plausible comparar estos estudios de acuerdo con un estimador puntual.

Tres estudios (63-65) con un $n=93$ en pacientes con patologías de hombro:

Guler et al. (63), con un $\mathrm{n}=40$ pacientes, comparó la efectividad de un programa de tratamiento con masaje Ciriax más movilización articular (grupo $n^{\circ} 1$ ) versus gru- po 2 con fisioterapia (CHC más OCC) en pacientes con capsulitis adhesiva primaria. Para la OCC no hubo cálculo de dosis, se realizaron 6 sesiones de 20 minutos cada una, 3 veces por semana, la duración total del tratamiento fue de 2 semanas, las medidas de resultado estudiadas fueron: dolor (EVA) y goniometría. El estudio no contempló seguimiento. Para la EVA ambos grupos muestran una mejoría significativa comparado con los datos basales $(\mathrm{p}<0,05)$, pero no existe diferencia significativa entre los grupos al finalizar el tratamiento, para las variables rango de movimiento de flexión anterior, rotación interna y externa existe diferencia significativa ( $\mathrm{p}<0,05)$, a favor del grupo $\mathrm{n}^{\circ} 1$ finalizado el tratamiento.

Jiménez et al. (64), con un $\mathrm{n}=23$ pacientes, comparó la efectividad de la iontoforesis con ácido acético más US y una pauta de ejercicios en domicilio versus un grupo con OCC, US y ejercicios en domicilio en pacientes con tendinopatía cálcica de hombro. Para la OCC no hubo cálculo de dosis, se realizaron 15 sesiones, 5 veces por semana, la duración total del tratamiento fue de 3 semanas, las medidas de resultado estudiadas fueron: dolor (EVA), funcionalidad (score de Constant) y evaluación radiológica. El estudio no contempló seguimiento. Para la EVA ambos grupos muestran una mejoría significativa comparado con los datos basales, pero no se encontró diferencia significativa entre los grupos $(\mathrm{p}=0,802)$; para el score de Constant, el grupo con iontoforesis no mostró una mejoría significativa con respecto a sus valores basales $(\mathrm{p}=0,108)$, a diferencia del grupo con OCC $(\mathrm{p}=0.02)$, tampoco hubo una disminución estadísticamente significativa en el tamaño de las calcificaciones al final del tratamiento para ninguno de los 2 grupos.

Leung et al. (65), con un $\mathrm{n}=30$ pacientes, comparó la efectividad de un programa de tratamiento con calor profundo (OCC) más ejercicios de estiramiento versus un grupo con calor superficial (CHC) más ejercicios de estiramiento versus un grupo control (solo con ejercicios) en pacientes con hombro congelado idiopático. Para la OCC no hubo cálculo de dosis, se realizaron 12 sesiones de 20 minutos cada una, 3 veces por semana, la duración total del tratamiento fue de 4 semanas, las medidas de resultado estudiadas fueron: funcionalidad (Shoulder Index score) y goniometría. El estudio contempló un seguimiento de 4 semanas. Para el Shoulder Index score hubo una diferencia significativa a favor del grupo OCC $(\mathrm{p}=0,046)$, para el rango de flexión anterior solo el grupo con OCC tuvo una mejoría significativa de los valores basales $(\mathrm{p}=0,002)$ y al compararlo con los otros grupos $(\mathrm{p}=0,031)$.

\section{Comparaciones entre diferentes dosis de $\mathrm{OC}$}

Seis estudios $(44,47,48,50,51,55)$, con un $n=417$ pacientes, investigaron la efectividad de las diferentes dosis de $\mathrm{OC}$ en pacientes con OA de rodilla. 
Callaghan et al. (44), con un $\mathrm{n}=27$ pacientes, comparó la efectividad de un grupo con bajas dosis de OCP (duración de pulso $200 \mu \mathrm{s}, 400$ pulsos por segundo y un Output $10 \mathrm{w}$ ), otro con altas dosis (duración del pulso de $400 \mu \mathrm{s}$, 400 pulsos por segundo y un Output 20 w) y un grupo control (OCP apagada) en pacientes con OA de rodilla. Para la OCP no hubo cálculo de dosis, se realizaron 6 sesiones de 20 minutos cada una, 3 veces por semana, la duración total del tratamiento fue 2 semanas, las medidas de resultado estudiadas fueron: dolor (EVA y AIMS), goniometría, funcionalidad (tiempo de caminar $13 \mathrm{~m}$ ), fuerza muscular (dinamómetro) e inflamación (radioleucocintigrafía). El estudio no contempló seguimiento. Debido al tamaño de la muestra, se realizó el análisis estadístico con Kruskal-Wallis para comparar los datos entre los grupos; finalizado el tratamiento, no hubo diferencia significativa para ninguna de las variables estudiadas ( $p>0,05)$, salvo el ROM de rodilla que fue clínica y estadísticamente significativo ( $p$ $=0,014$ ) a favor del grupo control, el tiempo de caminar $(\mathrm{p}=0,02)$ a favor del grupo de bajas dosis y la fuerza de cuádriceps $(\mathrm{p}=0,042)$ a favor del grupo de altas dosis.

Fukuda et al. (47), con un $\mathrm{n}=84$ pacientes, comparó la efectividad de un grupo con altas dosis de OCP (potencia máxima de $250 \mathrm{~W}$, duración del pulso $400 \mu \mathrm{s}$, frecuencia de pulso $145 \mathrm{~Hz}$, potencia media de $14,5 \mathrm{~W}, 38$ minutos con $33 \mathrm{KJ}$ de energía total), otro con bajas dosis de OCP (potencia máxima de $250 \mathrm{~W}$, duración del pulso $400 \mu \mathrm{s}$, frecuencia de pulso $145 \mathrm{~Hz}$, potencia media de 14,5 W, 19 minutos con $17 \mathrm{KJ}$ de energía total), un grupo placebo con la máquina apagada y un grupo control sin ninguna intervención. Se realizó cálculo de dosis para la potencia media (potencia máxima $\mathrm{x}$ duracion de pulso $\mathrm{x}$ frecuencia de pulso), se realizaron 9 sesiones 3 veces por semana, la duración total del tratamiento fue de 3 semanas, las medidas de resultado estudiadas fueron: dolor (EVA), funcionalidad (ALQ y escala de Lysholm) y ROM (goniometría). El estudio no contempló seguimiento. Al realizar la comparación entre los grupos, para la variable dolor medido con EVA el grupo de bajas dosis presenta una diferencia significativa comparado con el control $(p<0,005)$ y con el grupo de altas dosis $(\mathrm{p}<0,05)$; para el ALQ el grupo de altas dosis presenta diferencia significativa comparado con el placebo $(\mathrm{p}<0,005)$; la escala de Lysholm muestra diferencias significativas para el grupo de altas dosis ( $p$ $=0,0001)$ y de bajas dosis $(\mathrm{p}=0,001)$ comparado con el control, y grupo de altas dosis $(\mathrm{p}<0,05)$ y bajas dosis $(\mathrm{p}<$ 0,05 ) comparado con el placebo; para el ROM de flexión de rodilla hubo diferencia significativa entre el grupo de altas dosis $(\mathrm{p}<0,05)$, de bajas dosis $(\mathrm{p}=0,0001)$ y placebo $(\mathrm{p}$ $<0,05)$ comparado con el grupo control.

Fukuda et al. (48), con un $\mathrm{n}=121$ pacientes, comparó la efectividad de un grupo con altas dosis de OCP (potencia máxima de $250 \mathrm{~W}$, duración del pulso $400 \mu \mathrm{s}$, frecuencia de pulso $145 \mathrm{~Hz}$, potencia media de 14,5 W, 38 minutos con $33 \mathrm{KJ}$ de energía total), otro con bajas dosis de OCP (potencia máxima de $250 \mathrm{~W}$, duración del pulso $400 \mu \mathrm{s}$, frecuencia de pulso $145 \mathrm{~Hz}$, potencia media de 14,5 W, 19 minutos con $17 \mathrm{KJ}$ de energía total), un grupo placebo con la máquina apagada y un grupo control sin ninguna intervención. Se realizó cálculo de dosis para la potencia media (potencia máxima $\mathrm{x}$ duración de pulso $\mathrm{x}$ frecuencia de pulso), se realizaron 9 sesiones 3 veces por semana, la duración total del tratamiento fue de 3 semanas, las medidas de resultado estudiadas fueron: dolor (escala numérica de 11 puntos) y funcionalidad (KOOS). El estudio contempló un seguimiento a 12 meses. Al realizar la comparación entre los grupos finalizado el tratamiento, para la variable dolor solo el grupo de bajas dosis muestra una disminución significativa comparado con el placebo $(\mathrm{p}<0,01)$ y el control $(\mathrm{p}<0,05)$; para el KOOS el grupo de bajas dosis y el de altas dosis muestran un incremento significativo, en las subescalas de síntomas y actividades de la vida diaria, comparado con el placebo $(p<0,001)$ y control $(p<0,05)$, no existiendo diferencias significativas entre ningún grupo para las subescalas de dolor y calidad de vida $(\mathrm{p}>0,05)$. En el análisis de los resultados al finalizar el seguimiento, solo el grupo de bajas dosis muestra diferencia significativa comparado con el grupo placebo para la subescala de síntomas del KOOS ( $\mathrm{p}<0,05)$, para la subescala de actividades de la vida diaria $(\mathrm{p}<0,01)$, y la subescala de dolor $(\mathrm{p}<0,01)$, no existiendo diferencias significativas entre los demás grupos $(\mathrm{p}>0,05)$.

Laufer et al. (50), con un $\mathrm{n}=103$ pacientes, comparó la efectividad de un grupo con altas dosis de OCP (potencia máxima $200 \mathrm{~W}$, duración de pulso $300 \mu \mathrm{s}$, frecuencia de pulso $300 \mathrm{~Hz}$, potencia media de $18 \mathrm{~W}$ ), otro con bajas dosis de OCP (potencia máxima de $200 \mathrm{~W}$, duración de pulso $82 \mu \mathrm{s}$, frecuencia de pulso $110 \mathrm{~Hz}$, potencia media $1,8 \mathrm{~W})$ y un grupo placebo con la máquina apagada. Se realizaron 9 sesiones de 20 minutos cada una, 3 veces por semana, la duración total del tratamiento fue de 3 semanas, las medidas de resultado estudiadas fueron: funcionalidad (WOMAC, tiempo de levantarse y caminar, subir y bajar escaleras y caminar 3 minutos). El estudio contempló un seguimiento de 3 meses. Al realizar la comparación entre los grupos finalizado el tratamiento, para el WOMAC y el resto de las variables estudiadas no hubo diferencia significativa entre los grupos $(\mathrm{p}>0,05)$.

Ovanessian et al. (51), con un $\mathrm{n}=42$ pacientes, comparó la efectividad de un grupo con altas dosis de OCP (potencia máxima $250 \mathrm{~W}$, duración de pulso $400 \mu \mathrm{s}$, frecuencia de pulso $145 \mathrm{~Hz}$, potencia media de 14,5 W, 38 minutos con $33 \mathrm{KJ}$ de energía total), otro con bajas dosis de OCP (potencia máxima de $250 \mathrm{~W}$, duración del pulso $400 \mu \mathrm{s}$, frecuencia de pulso $145 \mathrm{~Hz}$, potencia media de 14,5 W, 19 minutos con $17 \mathrm{KJ}$ de energía total) y un grupo control sin ninguna intervención. Se realizó cálculo de dosis para la potencia media (potencia máxima $\mathrm{x}$ duración de pulso $\mathrm{x}$ 
frecuencia de pulso), se realizaron 9 sesiones 3 veces por semana, la duración total del tratamiento fue de 3 semanas, las medidas de resultado estudiadas fueron: dolor (EVA), funcionalidad (KOOS) y ROM (goniometría). El estudio no contempló seguimiento. Al realizar la comparación entre los grupos, para el dolor (EVA) el grupo de altas dosis $\mathrm{y}$ de bajas dosis presentan una disminución significativa comparado con el control $(p<0,05)$; en el KOOS, tanto en la subescala de dolor como en la de actividades de la vida diaria, el grupo de altas dosis y de bajas dosis muestran diferencias significativas con el control $(\mathrm{p}<0,05)$; para la subescala de deporte y recreación solo el grupo de bajas dosis muestra mejoría significativa comparado con el control $(\mathrm{p}<0,05)$, pero la comparación entre ambos grupos activos no muestra diferencia significativa en ninguna de las variables estudiadas $(\mathrm{p}>0,05)$.

Tuzun et al. (55), con un $\mathrm{n}=40$ pacientes, comparó la efectividad de un grupo con bajas dosis de OCP (potencia máxima de $1000 \mathrm{~W}$, frecuencia de pulso $20 \mathrm{~Hz}$, potencia media de $8 \mathrm{~W}$ ) versus un grupo de altas dosis de OCP (potencia máxima $600 \mathrm{~W}$, frecuencia de pulso $110 \mathrm{~Hz}$ y potencia media de $26,4 \mathrm{~W}$ ). Se realizaron 10 sesiones de 15 minutos cada una, 5 veces por semana, con una duración total del tratamiento de 2 semanas, las medidas de resultado estudiadas fueron: dolor (EVA), funcionalidad (tiempo de caminar $25 \mathrm{~m}$ ), ROM de rodilla (goniometría) y fuerza muscular (método de DeLorme). El estudio no contempló seguimiento. Si bien es cierto que ambos grupos muestran mejoría significativa de todas las variables al finalizar el tratamiento, al realizar la comparación entre los grupos no hubo diferencia clínica ni estadística para ninguna de las variables estudiadas $(p>0,05)$.

Si bien es cierto que los estudios $(47,48,51)$ usaron las mismas dosis de OCP en pacientes que eran clínicamente similares (OA crónica de rodilla), los tres estudios tenían un grupo con altas dosis, con bajas dosis y un control, midieron el dolor con EVA y escala numérica de 10 puntos. Sin embargo, las publicaciones no reportaban los valores de los diferentes grupos, por lo cual se contactó a los autores de manera de requerir esta información, se pudo establecer contacto vía correo electrónico con el Sr. Thiago Fukuda, quien nos respondió que no contaba con los datos grupales de la medición de dolor; por esta razón, no pudimos agrupar los datos de estos 3 estudios en un estimador puntual, para ver la posibilidad de realizar un metaanálisis.

\section{DISCUSIÓN}

Se intentó determinar si existe evidencia científica que avale la efectividad analgésica de la onda corta en patologías musculoesqueléticas de curso agudo y/o crónico. Para lograr nuestros objetivos, se realizó una síntesis de la evidencia disponible en las bases de datos, Medline, PEDro,
Central, Cinahl y Lilacs, con el fin de actualizar y ampliar los límites de búsqueda de las RS ya publicadas en la literatura que habían estudiado previamente el tema $(11,37,38)$.

Pese a lo común que resulta su indicación y/o uso en la práctica clínica para el manejo del dolor musculoesquelético, desde el año 2000 hasta la fecha solo se pudieron seleccionar 26 ECAs que cumplieron con los criterios de elegibilidad requeridos en nuestra RS. Para realizar el análisis de la información reportada por estos estudios, se intentó agrupar los datos de 6 artículos $(46,52,56,57,59,62)$ en 3 comparaciones que aparentemente eran homogéneas desde el punto de vista clínico. Sin embargo, luego del análisis de la información extraída, los autores de la presente RS decidieron que no era plausible juntar los estudios es un estimador puntual. Para el caso de 3 artículos $(47,48,51)$ que eran clínicamente homogéneos, se contactó a los autores para requerir información adicional, a la que finalmente no tuvimos acceso; por lo tanto, tampoco se pudo realizar un metaanálisis. Para el resto de los estudios seleccionados, debido a la variedad de las intervenciones estudiadas, las comparaciones, las dosis aplicadas, las medidas de resultado ocupadas y el seguimiento de estas, se hace imposible poder agruparlos y combinarlos estadísticamente de acuerdo con un estimador puntual.

Para analizar la calidad metodológica de los artículos incluidos en nuestra RS, se usó la escala de PEDro (66). De acuerdo a la evaluación efectuada por los autores de esta revisión, 12 artículos fueron evaluados de alta calidad metodológica ( $\geq 6$ puntos): Akyol et al. (40), Atamaz et al. (42), Bezalel et al. (43), Callaghan et al. (44), Cetin et al. (46), Fukuda et al. (48), Laufer et al. (50), Rattanachaiyanont et al. (52), Dziedzic et al. (56), Ahmed et al. (59), Guler et al. (63), Leung et al. (65). 13 artículos fueron evaluados de moderada calidad metodológica (4 y 5 puntos): Atamaz et al. (41), Cantarini et al. (45), Fukuda et al. (47), Jan et al. (49), Ovanessian et al. (51), Shakoor et al. (53), Silva et al. (54), Tuzun et al. (55), Lewis et al. (57), Bindal et al. (60), Kumar et al. (61), Shakoor et al. (62), Jiménez et al. (64). Por último, solo un artículo fue evaluado de baja calidad metodológica ( $\leq 3$ puntos): Buzzard et al. (58).

Cabe consignar que si bien es cierto que los 26 artículos seleccionados se reportaban como estudios clínicos "aleatorizados", en solo 10 de ellos $(40,42-44,48,52,56,61,62,65)$ se explicitaba en el texto la forma como se había realizado la aleatorización y en solo 5 artículos $(40,44,48,52,56)$ la aleatorización fue oculta, 8 de los artículos seleccionados $(47,51,53,54,57-59,61)$ no realizaron una comparación estadística inicial entre los grupos de estudio, como manera de asegurarse de que estos eran comparables al inicio del tratamiento, en 5 artículos $(42,48,50,52,59)$ fueron cegados los pacientes y en solo 2 artículos $(51,54)$ fueron cegados los terapeutas. Si bien es cierto que la mayoría de los estudios presentan pérdidas de pacientes durante el tiempo de tratamiento y/o seguimiento, solo $7(42,43,48,52,56,57,60)$ 
contemplaron dentro de su diseño metodológico un análisis estadístico por intención de tratar (AIT), 16 de los artículos seleccionados $(40,43-47,49,51,54,55,58,60,61,63-65)$ tienen una cantidad menor o igual a 30 pacientes por cada grupo de estudio, solo 6 artículos $(42,44,48,52,56,63)$ describen el uso de algún método y/o fórmula para realizar el cálculo del tamaño muestral y solo 2 de los artículos seleccionados $(48,56)$ tienen inscrito su protocolo en alguno de los sistemas de registro existentes en la actualidad, como manera de poder cotejar los datos de la planificación metodológica de los estudios previos a su realización.

Tradicionalmente los efectos terapéuticos descritos para la OC han sido avalados por textos, estudios de laboratorio, con animales y/o sujetos sanos; son muy pocos los estudios que han podido demostrar su efectividad clínica en pacientes con alguna patología de origen musculoesquelético. $\mathrm{Al}$ revisar la literatura, encontramos una revisión publicada en el año 1999, que estudió la eficacia de la diatermia por OC en pacientes con osteoartritis (OA) de rodilla (37). De los 11 artículos seleccionados, solo 3 de ellos (74-76) presentaron resultados razonablemente favorables; 5 (77-81) muestran resultados cuestionables y los 3 restantes (8284) presentaron resultados negativos. Los autores de esta revisión concluyen que los resultados contradictorios y la pobre calidad metodológica de los estudios seleccionados no permite establecer eficacia de la OC continua y/o pulsada en pacientes con OA de rodilla. Cuando estábamos finalizando el presente trabajo se publicó una nueva RS (85), cuyo objetivo también fue medir la efectividad de la OC en pacientes con OA de rodilla. Esta RS puso como criterio adicional de inclusión que los estudios tuvieran un score de PEDro $\geq 6$ puntos; de acuerdo con esto, solo se seleccionaron 7 artículos para el análisis final $(40,44,46,48,50,52,84)$ y pese a la gran variabilidad existente entre estos estudios (dosis, duración, tratamientos y comparaciones), los autores igual consideraron pertinente realizar un metaanálisis. Desde nuestra perspectiva, es muy difícil poder interpretar los resultados de un metaanálisis, cuando los estudios no son homogéneos desde el punto de vista clínico, cuando las comparaciones no son similares y, además, sin haber evaluado previamente la homogeneidad estadística (chi2) y/o la heterogeneidad (Test de inconsistencia I2). Aun así, ellos concluyen que en pacientes con OA de rodilla hay efectos significativos pequeños en el dolor y rendimiento muscular, solo cuando la OC produce una sensación térmica local.

En base a la información extraída de los estudios seleccionados en nuestra RS, cuando la OC se estudiaba en forma aislada o incluida en un programa de tratamiento, consideramos un resultado favorable, cuando el grupo que era intervenido con $\mathrm{OC}$ mostraba diferencia clínica y estadísticamente significativa, comparado con un grupo control y/o otros grupos de estudio, de acuerdo a lo anterior, 7 ECAs mostraron resultados favorables $(49,41,46,59,62,65,64)$; seis de los cuales usaron OCC, ya sea en forma aislada (49) o OCC en conjunto con otras intervenciones $(46,59,62,64,65)$, ninguno realizó cálculo de dosis, y salvo 2 estudios $(59,62)$, el resto todos difieren en número de sesiones, tiempo de aplicación y duración del tratamiento, el promedio de sesiones de estos estudios fue de 18,9 (DS 6,1). 4 estudios $(46,59,62,64)$ no contemplaron seguimiento, 2 fueron a corto plazo $(49,65)$ y solo 1 fue a largo plazo (41) (1 año), 3 se realizaron en pacientes con OA crónica de rodilla $(49,41,46), 2$ en síndrome de dolor lumbar crónico $(59,62)$ y 2 en patologías de hombro $(64,65)$.

Por el contrario, 12 fueron los ECAs que presentaron resultados desfavorables $(58,43,45,40,61,42,52,54,56,57$, $60,63)$. Vale decir que al realizar la comparación entre los grupos de estudio, no hubo diferencia clínica y estadísticamente significativa en favor del que se aplicaba OC, esto independiente que dentro de cada grupo los pacientes hayan mostrado mejoría de sus mediciones basales al finalizar el tratamiento y/o el seguimiento, es conveniente mencionar que en solo 5 de estos artículos, la OC se estudió como objetivo primario del ECA $(40,52,54,56,58), 8$ usaron OCC $(40,42,43,45,52,54,61,63)$ y 4 OCP $(56,57,58,60)$, ninguno realizó cálculo de dosis, todos los estudios tenían intervenciones, comparaciones, número de sesiones, tiempo de aplicación y duración del tratamiento diferentes, el promedio de sesiones fue de 11,1 (DS 3,9), valor que es significativamente menor $(\mathrm{p}<0,05)$ que el grupo de estudios con resultados favorables.

Consideramos pertinente realizar en forma separada la discusión de los 6 ECAs $(44,47,48,50,51,55)$, que estudiaron la efectividad de la $\mathrm{OC}$ en pacientes con OA crónica de rodilla, a través de la comparación de diferentes dosis de OCP con un grupo placebo (máquina apagada) y/o control (sin intervención). El uso de OCP para el tratamiento articulaciones artríticas y/o artrósicas se ha incrementado considerablemente en las últimas décadas, esto debido a la probable asociación entre el aumento de la temperatura que produce la OCC y el aumento de la actividad inflamatoria sinovial, y entre la actividad inflamatoria sinovial y el empeoramiento de la degeneración del cartílago en pacientes con OA $(11,86)$. Estudios recientes realizados en Inglaterra (87) e Irlanda (12) muestran un aumento considerable en la indicación y uso por parte de los fisioterapeutas de la OCP en comparación con la OCC, aunque gran parte de los efectos terapéuticos asociados a la OCP no han podido ser corroborados por estudios clínicos y los publicados son generalmente de baja calidad metodológica, con serios problemas en los parámetros de dosificación, los cuales muchas veces ni siquiera son informados. La evidencia en estudios experimentales ha mostrado que la OCP también produce elevación de la temperatura de los tejidos expuestos, pero es dependiente de la potencia media entregada $(25,26)$, que según los estudios se puede obtener a 10,9 W (DS 3,2) (88), y puede variar en un rango entre posible sensación térmica 
de 13,8 W (DS 7,1) y definitiva sensación térmica a 21,2 W (DS 8,3) (26). Al-Mandeel y Watson (27) demostraron efectos fisiológicos significativos en el flujo sanguíneo y en la temperatura de la piel a $24 \mathrm{~W}$ en comparación a $3 \mathrm{~W}$ de potencia media, lo que corrobora que los efectos de la OCP son dosis dependientes. De todos los estudios seleccionados por nuestra RS, solo 3 realizaron cálculo de dosis para la administración de OCP $(47,48,51)$. Cabe consignar que los tres muestran resultados favorables. Para realizar el cálculo primero se sacó la potencia media (Pm); $[\mathrm{Pm}(\mathrm{W})$ = Potencia peak o máxima $(\mathrm{W}) \mathrm{x}$ duración de pulso $(\mathrm{seg}) \mathrm{x}$ frecuencia de pulso $(\mathrm{Hz})](11)$, luego se calculó la energía total entregada; $[\mathrm{E}(\mathrm{J})=\mathrm{Pm}(\mathrm{W}) \times$ tiempo total de tto. (s)] (89). Sería importante considerar que, si bien es cierto que el tiempo de aplicación de la $\mathrm{OC}$, el número de sesiones y la periodicidad del tratamiento a veces suelen ser similares, existen factores que podrían contribuir a la explicación de los resultados controversiales, la potencia media y la energía total de los estudios que presentan resultados desfavorables son muy diferentes. Callaghan et al. (44) comparó $20 \mathrm{~W}$ - $24 \mathrm{KJ}$ versus $10 \mathrm{~W}-12 \mathrm{KJ}$; Laufer et al. (50) comparó $18 \mathrm{~W}-21,6 \mathrm{KJ}$ versus $1,8 \mathrm{~W}-2,1 \mathrm{KJ}$; Tuzun et al. (55) comparó 26,4 W-23,7 KJ versus $8 \mathrm{~W}$ - 7,2 KJ, además es necesario determinar el peso real de las cointervenciones y como contribuyen estas en el objetivo del estudio, sobre todo considerando que existe una tendencia en la literatura a usar la OC solo como control.

Todas estas consideraciones deben ser cuidadosamente evaluadas cuando se interpreten los resultados de los diferentes estudios y se intenten establecer conclusiones acerca de la efectividad clínica de la OC en el manejo clínico de las diferentes patologías musculoesqueléticas.

\section{CONCLUSIONES}

La gran variabilidad existente en las intervenciones terapéuticas, las dosis ocupadas, la periodicidad de los tratamientos, las variables estudiadas y el seguimiento de estas hace que sea imposible extraer conclusiones definitivas acerca de la efectividad clínica de la OC en el manejo analgésico de patologías músculoesqueléticas.

La heterogeneidad clínica que se presentaba al tratar de realizar alguna comparación en los artículos seleccionados por nuestra RS no permitieron el agrupamiento estadístico de los datos de acuerdo con un estimador puntual. Aun así, igual se consideró pertinente realizar un agrupamiento cualitativo o descriptivo de los resultados en las intervenciones clínicamente similares, situación que es muy difícil de evaluar para realizar el análisis final, ya que la interpretación de los resultados en los estudios pequeños, aunque parezcan metodológicamente correctos, carecen de un poder estadístico que proporcione pruebas concluyentes como para establecer efectividad clínica de una interven- ción por sobre otra y que además permita extrapolar estos resultados en otro contexto clínico.

En pacientes con OA crónica de rodilla, existe moderada evidencia a corto y largo plazo de que la OCP a dosis altas $(33 \mathrm{KJ})$ y bajas $(17 \mathrm{KJ})$ es más efectiva en la mejora del dolor y la función que el placebo (máquina apagada) y el control sin intervención. Al comparar entre las dosis a corto plazo la evidencia es contradictoria que $17 \mathrm{KJ}$ sea más efectiva en el dolor que $33 \mathrm{KJ}$, pero a largo plazo existe moderada evidencia de que $17 \mathrm{KJ}$ es más efectiva que 33 KJ. Existe moderada evidencia a corto plazo de que no existe diferencia clínica ni significativa en el dolor, entre altas dosis de OCP $(20 \mathrm{~W})$ versus bajas dosis $(10 \mathrm{~W})$ y un control, ni en la función cuando se compara $(18 \mathrm{~W})$ versus $(1,8 \mathrm{~W})$ con una máquina apagada.

Existe moderada evidencia a corto, mediano y largo plazo de que un programa de tratamiento de 15 sesiones con agentes físicos (OCP, IR y terapia interferencial) es más efectivo que un grupo con inyecciones intraarticulares, en la disminución del dolor nocturno, en reposo y SF-36.

Existe limitada evidencia a corto plazo de que 30 sesiones de OCC es igualmente efectiva que 30 sesiones de OCC más AINEs, en la disminución del dolor y la inflamación en pacientes con sinovitis producto de la OA de rodilla.

Existe evidencia controversial de que a corto plazo adicionar OCC a un programa de ejercicio isocinético disminuya el dolor y mejore la función comparado con ejercicio isocinético solo.

Existe moderada evidencia a corto y mediano plazo de que adicionar OCC a un programa de ejercicios y educación no disminuye el dolor ni reduce el consumo de analgésicos, no mejora la función ni el rango de movimiento.

Existe moderada evidencia de que a corto plazo un programa educacional más ejercicios en domicilio es más efectivo en la mantención de la funcionalidad a las 4 semanas, comparado con 6 sesiones de OCC; y que un programa de tratamiento de 15 sesiones de spa con compresas de barro más baños de aguas minerales es más efectivo en la mantención de la reducción del dolor y consumo de analgésicos a las 12 semanas, comparado con 10 sesiones de OCC.

Existe limitada evidencia a corto plazo de que la crioterapia más ejercicios es más efectiva que 10 sesiones de OCC más ejercicios, en la reducción del dolor.

En pacientes con síndrome de dolor lumbar, existe moderada evidencia a corto plazo de que adicionar OCC a un programa terapéutico con AINEs y ejercicios produce una disminución del dolor desde la $3^{\mathrm{a}}$ semana de tratamiento en pacientes con SDL crónico. La evidencia es limitada a corto plazo, que las técnicas de estabilización dinámica muscular son igualmente efectivas en la disminución del dolor que un programa de tratamiento convencional de 18 sesiones con OCC, US y ejercicios de fortalecimiento muscular, y que 15 sesiones de OCP más ejercicios son igualmente efectivas que un programa de yoga en sujetos jóvenes con SDL. 
En pacientes con dolor cervical inespecífico, existe moderada evidencia a mediano plazo de que adicionar OCP a un programa de ejercicios no añade ningún beneficio en la reducción del dolor y la percepción de mejoría global.

En pacientes con capsulitis adhesiva primaria de hombro, existe moderada evidencia a corto plazo de que OCC más CHC es igualmente efectiva que el masaje Ciriax más movilización articular, en la disminución del dolor, pero no en la mejoría del ROM de flexión anterior, rotación interna y externa de hombro; y que adicionar OCC a ejercicios de estiramiento es más efectivo en la mejoría de la funcionalidad y el ROM de flexión anterior, comparado con las CHC y ejercicios solos.

En pacientes con tendinopatía cálcica de hombro, existe limitada evidencia a corto plazo de que la OCC produce una mejoría del dolor y la función en comparación a la iontoforesis con ácido acético.

En pacientes con fractura de calcáneo, existe limitada evidencia de que a corto plazo, la OCP es igualmente efectiva que la crioterapia con Cryocuff, en la mejoría del ROM y la disminución del edema de tobillo a los 5 días de retirada la inmovilización.

Los resultados arrojados por nuestra revisión no deberían ser tomados como fundamento para no indicar y/o usar $\mathrm{OC}$ en pacientes con patologías de origen musculoesquelético, sino más bien debieran ser tomado como un desafío para todos los profesionales que participan en el proceso de rehabilitación de estos pacientes, ya que el fomento y desarrollo de la investigación clínica es una de las maneras de poder de asentar y validar nuestros esquemas terapéuticos, si bien es cierto que esto representa un desafío desde el punto de vista profesional y metodológico, es necesario para el aseguramiento de calidad asistencial y el éxito terapéutico de nuestros pacientes.

Pese a lo extenso de la estrategia de búsqueda, siempre es posible que no se haya identificado algún estudio, la obtención del material no publicado o "literatura gris" es una de las principales limitantes de nuestra revisión. Cabe consignar que las conclusiones de nuestro estudio se realizaron sobre la base de los artículos localizados por nuestra estrategia de búsqueda y seleccionados por nuestros criterios de elegibilidad; aun así, siempre se debe tomar en cuenta la probabilidad de que existan estudios que por problemas de indexación o límites de búsqueda hayan quedado fuera de esta revisión. Por último se agradece a los autores que en forma desinteresada proporcionaron información adicional para realizar esta presente RS.

\section{CORRESPONDENCIA:}

Héctor Gutiérrez E.

e-mail: kinehector@gmail.com

\section{BIBLIOGRAFÍA}

1. Cameron MH. Physical agents in rehabilitation: From research to practice. Philadelphia: W.B. Saunders; 3 Ed. 2009.

2. D'Arsonval A. Action physiologique des courants alternatives a grande frequence. Arch Electric Med 1897;6:133.

3. Hitchcock RT, Patterson RM. Radio-frequency and ELF electromagnetic energies: A handbook for health professionals, New York 1985, Van Nostrand Reinhold.

4. Goats G. Continuous short-wave (radio-frequency) diathermy Br I Sports Med 1989;23:123-7.

5. Low J, Reed A. Electrotherapy explained. 3rd ed. Oxford: Butterworth-Heinemann; 2000.

6. Cole AJ, Eagleston RA. The benefits of deep heat: Ultrasound and electromagnetic diathermy. Physician Sportsmed 1994;22(2):76-88.

7. Michlovitz S. Thermal Agents in Rehabilitation. 3rd ed. Philadelphia, PA: FA Davis; 1996:168-254.

8. Draper D, Castel J, Castel D. Rate of temperature increase in human muscle during $1 \mathrm{MHz}$ and $3 \mathrm{MHz}$ continuous ultrasound. J Orthop Sports Phys Ther 1995;22:142-50.

9. Lehmann J, McDougall J, Guy A, Warren C, Esselman P. Heating patterns produced by shortwave diathermy applicators in tissue substitute models. Arch Phys Med Rehabil 1983;64:575-7.

10. Garrett C, Draper D, Knight K. Heat distribution in the lower leg from pulsed short wave diathermy and ultrasound treatments. J Athl Train 2000;35(1):50-5.

11. Kitchen S, Partridge C. Review of shortwave diathermy continuous and pulsed patterns. Physiotherapy 1995;78:243-52.

12. Shields N, Gormley J, O'Hare N. Short-wave diathermy: Current clinical and safety practices. Physiother Res Int 2002;7:191-202.

13. Goats G. Pulsed electromagnetic (short-wave) energy therapy. Br J Sports Med 1989;23(4):213-6.

14. Oliver, D.E. Pulsed electromagnetic energy-what is it? Physiotherapy 1984;70(12):458-9.

15. Low, J.L. The nature and effects of pulsed electromagnetic radiations. New Zealand I Physiotherapy; 1978;18-22.

16. Lehmann J.Therapeutic Heat and Cold, 4th ed. Baltimore: Williams \& Wilkins; 1990;471-581.

17. Wilson DH. Treatment of soft tissue injuries by pulsed electrical energy. Br Med 1 1972;2:269-70.

18. McCray RE, Patton NJ. Pain relief at trigger points: Comparison of moist heat and shortwave diathermy. J Orthop Sports Phys Ther 1984;5:175-8.

19. Brown M, Baker RD. Effect of pulsed short wave diathermy on skeletal muscle injury in rabbits. Phys Ther 1987;67:208-13.

20. Chapman CE. Can the use of physical modalities for pain control be rationalized by the research evidence? Can J Physiol Pharmacol 1991;69:704-12.

21. Hayne C. Pulsed frequency energy, its place in physiotherapy. Physiotherapy 1984;70:259-66.

22. Watson T. Electrotherapy: Evidence Based Practice, Chapter 10, 12th ed. Edinburgh, UK: Churchill Livingstone; 2008; 137-160.

23. Evans P. The healing process at cellular level: a review. Physiotherapy 1980;66:256-69.

24. Bricknell R, Watson T. The thermal effects of pulsed shortwave diathermy. British Journal of Therapy and Rehabilitation 1995;2:430-4.

25. Draper D, Knight K, Fujiwara T, Castel C. Temperature change in human muscle during and after pulsed short-wa- 
ve diathermy. J Orthop Sport Phys Ther 1999;29(1):13-18; discussion 19-22.

26. Murray CC, Kitchen S. Effect of pulse repetition rate on the perception of thermal sensation with pulsed shortwave diathermy. Physiother Res Int 2000;5:73-84.

27. Al-Mandeel M, Watson T. The thermal and nonthermal effects of high and low doses of pulsed short wave therapy (PSWT). Physiother Res Int 2010;15:199-211.

28. Hill J, Lewis M, Mills P, Kielty C. Pulsed short-wave diathermy effects on human fibroblast proliferation. Arch Phys Med Rehabil 2002;83:832-5.

29. Wang JL, Chan RC, Cheng HH, Huang CJ, Lu YC, Chen IS, et al. Short waves induced enhancement of proliferation of human chondrocytes: Involvement of extra-cellular signal-regulated map-kinase. Clin Exp Pharmacol Physiol 2007;34(7):581-5.

30. Kitchen S, Partridge C. A survey to examine the clinical use of ultrasound, shortwave diathermy and laser in England. British Journal of Therapy and Rehabilitation 1996;3(2):644-50.

31. Pope G, Mockett S, Wright J. A survey of electrotherapeutic modalities: Ownership and use in NHS in England. Physiotherapy 1995;8(2):82-91.

32. Al-Mandeel M, Watson T. An evaluative audit of patients' records in electrotherapy with specific reference to pulsed short wave therapy. International Journal of Therapy and Rehabilitation 2006;13(9):414-9.

33. Robertson V, Spurritt D. Electrophysical agents: Implications of their availability and use in undergraduate clinical placements. Physiotherapy 1998;84:335-44.

34. Philadelphia Panel evidence-based clinical practice guidelines on selected rehabilitation interventions for low back pain. Phys Ther 2001;81(10):1641-74.

35. Philadelphia Panel evidence-based clinical practice guidelines on selected rehabilitation interventions for neck pain. Phys Ther 2001;81(10):1701-17.

36. Philadelphia Panel evidence-based clinical practice guidelines on selected rehabilitation interventions for shoulder pain. Phys Ther 2001;81(10):1719-30.

37. Marks R, Ghassemi M, Duarte R, van Nguyen JP. A review of the literature on shortwave diathermy as applied to osteo-arthritis of the knee. Physiotherapy 1999;85(6):304-16.

38. Shields N, Gormley J, O'Hare N. Short-wave diathermy: a review of existing clinical trials. Physical Therapy Reviews 2001;6:101-18.

39. Higgins JPT, Green S (editors). Cochrane Handbook for Systematic Reviews of Interventions Version 5.0.2 [updated September 2009]. The Cochrane Collaboration, 2009. Available from www.cochrane-handbook.org.

40. Akyol Y, Durmus D, Alayli G, Tander B, Bek Y, Canturk F et al. Does short-wave diathermy increase the effectiveness of isokinetic exercise on pain, function, knee muscle strength, quality of life, and depression in the patients with knee osteoarthritis? A randomized controlled clinical study. Eur J Phys Rehabil Med 2010; 46(3):325-36.

41. Atamaz F, Kirazli Y, Akkoc Y. A comparison of two different intra-articular hyaluronan drugs and physical therapy in the management of knee osteoarthritis. Rheumatol Int 2006;26(10):873-8.

42. Atamaz F, Durmaz B, Baydar M, Demircioglu O, Iyiyapici A, Kuran B et al. Comparison of the efficacy of transcutaneous electrical Nerve Stimulation, Interferential currents, and shortwave diathermy in knee osteoarthritis: A double-blind, randomized, controlled multicenter study. Arch Phys Med Rehabil 2012 May;93(5):748-56.
43. Bezalel T, Carmeli E, Katz-Leurer M. The effect of a group education programme on pain and function through knowledge acquisition and home-based exercise among patients with knee osteoarthritis: A parallel randomised single-blind clinical trial. Physiotherapy 2010;96(2):137-43.

44. Callaghan MJ, Whittaker PE, Grimes S, Smith L. An evaluation of pulsed shortwave on knee osteoarthritis using radioleucoscintigraphy: A randomised, double blind, controlled trial. Joint Bone Spine 2005;72:150-5.

45. Cantarini L, Leo G, Giannitti C, Cevenini G, Barberini P, Fioravanti A. Therapeutic effect of spa therapy and short wave therapy in knee osteoarthritis: A randomized, single blind, controlled trial. Rheumatol Int 2007;27(6):523-9.

46. Cetin N, Aytar A, Atalay A, Akman MN. Comparing hot pack, short-wave diathermy, ultrasound, and TENS on isokinetic strength, pain, and functional status of women with osteoarthritis knees: A single-blind, randomized, controlled trial. Am J Phys Med Rehabil 2008;87(6):443-51.

47. Fukuda TY, Ovanessian V, Cunha RA, Filho ZJ, Cazarini C, Rienzo F et al. Pulsed short wave effect in pain and Function in patients with knee osteoarthritis. Journal Applied Research 2008;8(3):189-98.

48. Fukuda TY, Alves da Cunha R, Fukuda VO, Rienzo FA, Cazarini C, Carvalho NAA, et al. Pulsed shortwave treatment in women with knee osteoarthritis: A multicenter, randomized, placebo-controlled clinical trial. Phys Ther 2011;91(7):1009-17.

49. Jan MH, Chai HM, Wang CL, Lin YF, Tsai LY. Effects of repetitive shortwave diathermy for reducing synovitis in patients with knee osteoarthritis: An ultrasonographic study. Phys Ther 2006;86(2):236-44.

50. Laufer Y, Zilberman R, Porat R, Nahir AM. Effect of pulsed short-wave diathermy on pain and function of subjects with osteoarthritis of the knee: A placebo-controlled double-blind clinical trial. Clin Rehabil 2005;19(3):255-63.

51. Ovanessian V, Cazarini C, Alves de Cunha R, Carvalho N, Fukuda T. Use of different doses of pulsed short waves in the treatment of patients with osteoarthritis of the knee. Rev. Cienc. Med. Campinas 2008;17(3-6):149-55.

52. Rattanachaiyanont M, Kuptniratsaikul V. No additional benefit of shortwave diathermy over exercise program for knee osteoarthritis in peri-/post-menopausal women: An equivalence trial. Osteoarthritis Cartilage 2008;16(7):823-8.

53. Shakoor MA, Taslim MA, Hossain MS. Effects of activity modification on the patients with osteoarthritis of the knee. Bangladesh Med Res Counc Bull. 2007;33(2):55-9.

54. Silva AL, Imoto DM, Croci AT. Comparison of cryotherapy, exercise and short waves for in knee osteoarthritis treatment. Acta Orthop Bras. [serial on the Internet]. 2007;15(4):204-9.

55. Tuzun EH, Otman S, Kirdi N. Comparison of different methods of pulsed shortwave diathermy in knee osteoarthritis. Pain Clinics 2003;15(4):421-7.

56. Dziedzic K, Hill J, Lewis M, Sim J, Daniels J, Hay EM. Effectiveness of Manual Therapy or Pulsed Shortwave Diathermy in Addition to Advice and Exercise for Neck Disorders: A Pragmatic Randomized Controlled Trial in Physical Therapy Clinics. Arthritis Rheum 2005;15;53(2):214-22.

57. Lewis M, James M, Stokes E, Hill J, Sim J, Hay E et al. An economic evaluation of three physiotherapy treatments for non-specific neck disorders alongside a randomized trial. Rheumatology 2007;46(11):1701-8.

58. Buzzard BM, Pratt RK, Briggs PJ, Siddique MS, Tasker A, Robinson S. Is Pulsed Shortwave Diathermy Better than Ice 
Therapy for the Reduction of Oedema following Calcaneal Fractures? Physiotherapy 2003;89(12):734-42.

59. Ahmed MS, Shakoor MA, Khan AA. Evaluation of the effects of shortwave diathermy in patients with chronic low back pain. Bangladesh Med Res Counc Bull 2009;35:18-20.

60. Bindal VD, Ghay GD. Comparative Efficacy of Selected Physiotherapy Treatment and Yogic Asanas on Low Back Pain among Male Physical Education Students. Journal of Exercise Science and Physiotherapy 2007;3(2):160-4.

61. Kumar S, Sharma VP, Negi MP. Efficacy of dynamic muscular stabilization techniques (DMST) over conventional techniques in rehabilitation of chronic low back pain. J Strength Cond Res 2009;23(9):2651-9.

62. Shakoor MA, Rahman MS, Moyeenuzzaman M. Effects of deep heat therapy on the patients with chronic low back pain Mymensingh Med J 2008;17(2 Supl.):S32-8.

63. Guler FU, Kozanoglu E. Comparison of the early response to two methods of rehabilitation in adhesive capsulitis. Swiss Med Wkly 2004;134(23-24):353-8.

64. Jiménez D, López E, López M. Tratamiento de la tendinopatía calcificante de hombro: ¿iontoforesis con ácido acético u onda corta? Rehabilitación 2008;42(5):239-45.

65. Leung M, Cheing G. Effect of Deep and superficial heating in the management of frozen shoulder. J Rehabil Med 2008;40:145-50.

66. PEDro (Physiotherapy Evidence Database). [consultado 30/11/2012]. Disponible en: http://www.pedro.fhs.usyd.edu. $\mathrm{au} / \mathrm{spanish} /$ scale_item_spanish.htlm.

67. Maher CG, Sherrington C, Herbert RD, Moseley AM, Elkins M: Reliability of the PEDro scale for rating quality of randomized controlled trials. Phys Ther 2003;83(8):713-21.

68. Macedo LG, Elkins MR, Maher CG, Moseley AM, Herbert RD, Sherrington C: There was evidence of convergent and construct validity of Physiotherapy Evidence Database quality scale for physiotherapy trials. J Clin Epidemiol 2010;63:920-25.

69. De Morton NA: The PEDro scale is a valid measure of the methodological quality of clinical trials: A demographic study. Aust J Physiother 2009;55:129-33.

70. Bhogal SK, Teasell RW, Foley NC, Speechley MR: The PEDro scale provides a more comprehensive measure of methodological quality than the Jadad scale in stroke rehabilitation literature. J Clin Epidemiol 2005;58:668-73.

71. Maher CG. A systematic review of workplace interventions to prevent low back pain. Aust J Physiother 2000;46:259-69.

72. Elkins MR, Herbert RD, Moseley AM, Sherrington C, Maher C. Rating the quality of trials in systematic reviews of physical therapy interventions. Cardiopulm Phys Ther J 2010;21:20-26.

73. Van Tulder M, Furlan A, Bombardier C, Bouter L. Editorial Board of the Cochrane Collaboration Back Review Group. Updated Method Guidelines for Systematic Reviews in the Cochrane Collaboration Back Review Group. Spine 2003;28(12):1290-9.

74. Wright V. Treatment of osteo-arthritis of the knees. Ann Rheum Dis 1964;23(5):389-91.

75. Valtonen EJ, Alaranta H. Comparative clinical study of the effect of short-wave and long-wave diathermy on osteo-arthritis of the knee and hip. Scand J Rehabil Med 1971;3(3):109-12.

76. Lankhorst GJ, van de Stadt RJ, van der Korst JK, Hinlopen-Bonrath E, Griffioen FM, de Boer W. Relationship of isometric knee extension torque and functional variables in osteoarthrosis of the knee. Scand J Rehabil Med 1982;14(1):7-10.

77. Hamilton DE, Bywaters EG, Please NW. A controlled trial of various forms of physiotherapy in arthritis. Br Med J 1959;1(5121):542-4.

78. Bansil CK, Joshi JB. Effectiveness of shortwave diathermy and ultrasound in the treatment of osteo-arthritis of the knee joint. Med J Zambia 1975;9(5):138-9.

79. Chamberlain MA, Care G, Harfield B. Physiotherapy in osteo-arthrosis of the knees. A controlled trial of hospital versus home exercises. Int Rehabil Med 1982;4(2):101-6.

80. Svarcova J, Trnavsky K, Zvarova J. The influence of ultrasound, galvanic currents and shortwave diathermy on pain intensity in patients with osteoarthritis. Scand J Rheumatol Supl. 1987;67:83-5.

81. Jan MH, Lai JS. The effects of physiotherapy on osteoarthritis knees of females. J Formos Med Assoc 1991;90(10):1008-13.

82. Clarke GR, Willis LA, Stenners L, Nichols PJ. Evaluation of physiotherapy in the treatment of osteoarthrosis of the knee. Rheumatol Rehabil 1974;13(4):190-7.

83. Quirk AS, Newman RJ, Newman KJ. An evaluation of interferential therapy, shortwave diathermy and exercise in the treatment of osteoarthrosis of the knee. Physiotherapy 1985;71(2):55-7.

84. Klaber Moffett JA, Richardson PH, Frost H, Osborn A. A placebo controlled double blind trial to evaluate the effectiveness of pulsed short wave therapy for osteoarthritic hip and knee pain. Pain 1996;67(1):121-7.

85. Laufer Y, Dar G. Effectiveness of thermal and athermal short-wave diathermy for the management of knee osteoarthritis: A systematic review and meta-analysis. Osteoarthritis Cartilage 2012;20(9):957-66.

86. Chikanza I, Fernandes L. Novel strategies for the treatment of osteoarthritis. Expert Opin Invest Drugs 2000;9:1499-510.

87. Shah S, Farrow A, Esnouf A. Availability and use of electrotherapy devices: A survey. Int J Ther Rehabil 2007;14:260-4.

88. Bricknell R, Watson T. The thermal effects of pulsed shortwave diathermy. Br J Ther Rehabil 1995;2:430-4.

89. Bjordal M, Couppé C, Chow R, Tunér J, Ljunggren E. A systematic review of the low level laser therapy with location-specific dosages for pain from chronic joint disorders. Australian J Physiother 2003;49(2):107-16. 